Türkiye Jeoloji Bülteni
Geological Bulletin of Turkey
$61(2018) 23-50$
doi:10.25288/tjb.358171

\title{
Kapadokya Bölgesi (Nevşehir, Orta Anadolu) Kalk-alkalen ve Alkalen Plütonik/ Subvolkanik Kayaçların Petrografik ve Jeokimyasal Özellikleri
}

Petrographic and Geochemical Features of Calc-alkaline and Alkaline Plutonic/Subvolcanic Rocks in the Cappadocia Region (Nevşehir, Central Anatolia)

\author{
Ayşe Orhan' ${ }^{1}$, Mehmet Demirbilek² $\mathbb{D}$ \\ ${ }^{1}$ Nevşehir Hacı Bektaş Veli Üniversitesi, Mühendislik ve Mimarlık Fakültesi, \\ Jeoloji Mühendisliği Bölümü, 50300 Nevşehir \\ ${ }^{2}$ Dumlupınar Üniversitesi, Mühendislik Fakültesi, \\ Jeoloji Mühendisliği Bölümü, 43100 Kütahya
}

Geliş/Received : 24.05.2017 • Düzeltilmiş Metin Geliş/Revised Manuscript Received : 26.07.2017 • Kabul/Accepted : 18.08.2017 • Bask1/Printed : 01.01 .2018 Araştırma Makalesi/Research Article Türkiye Jeol. Bül. / Geol. Bull. Turkey

Öz: Kapadokya Bölgesinde, Nevşehir'in kuzeyinde yüzeyleyen Bayramhac1, İdişdağı, Göynük, Karadağ, Yeşilöz, Akçataş plütonik ve/veya subvolkanik kayaçları ve güneyinde yüzeyleyen Acıgöl Plütonik kayaçları Orta Anadolu Granitoyidleri içerisinde yer alır. Nevşehir'in güneyinde yüzeyleyen Acıgöl plütonu monzogranit bileşimine sahip olup az oranda mafik mikrogranüler anklav (MME) ve iri-K.feldispat megakristalleri içermektedir. Kuzeyde yüzeyleyen magmatik kayaçlar ise monzogranit - kuvars monzonit / monzodiyorit - monzonit - fonolitik tefrit / tefritik fonolit arasında değişen farklı bileşimli kayaçlardan oluşmaktadır. Kuvars monzonit / monzodiyorit bileşimli kayaçlar sık sık MME ve iri-K.feldispat megakristalleri içermektedir. Monzonit bileşimli kayaçlar ise iri-K.feldispat veya lösit içeren porfirik dokulu subvolkanik kayaçlar ile dokanak halindedir.

Bölgedeki monzogranitik kayaçlar subalkalen, yüksek-K ve kalk-alkalen karakterli ve I-tipi löko-granit özelliğindedir. Kuvars monzonit, monzonit / monzodiyorit bileşimli kayaçlar subalkalen, yüksek-K ile kalk-alkalen ile şoşonitik arasında değişen ve I-tipi magma karakteri sunmaktadır. Monzonit ve fonolitik tefrit / tefritik fonolit bileşimli kayaçlar ise alkalen ve şoşonitik karakteri ile A-tipi magma karakteri sunmaktadır. Farklı bileşime sahip magmatik kayaçların iz element bollukları da farklılık sunar. Hafif nadir toprak element (HNTE) zenginleşme oranları monzogranit ((La/ $\left.\mathrm{Yb})_{\mathrm{n}}=4.58-12.11\right)$ bileşimli kayaçlardan kuvars monzonit / monzodiyorit $\left((\mathrm{La} / \mathrm{Yb})_{\mathrm{n}}=12.06-33.78\right)$ ve monzonit ve fonolitik tefrit / tefritik fonolit bileşimli $\left((\mathrm{La} / \mathrm{Yb})_{n}=23.29-82.17\right)$ kayaçlara doğru artma eğilimindedir. Okyanus sırtı granitlere göre normalize edilmiş element diyagramlarında, bütün magmatik kayaçlar büyük iyon çaplı litofil elementlerce (LILE: K, Rb, Ba) kalıcılığı yüksek elementlere göre (HFSE: Ta, Nb, Hf, Zr, Y) zenginleşme eğilimi ile magmanın yitim zonu ve/veya çarpışma ile ilişkili tektonik yerleşimden türediğine işaret eder. Alkalen magmatik kayaçlar kalk-alkali magmatik kayaçlara göre belirgin LIL (K, Rb, Ba, Th) ve HFS ( Ta, Nb, Ce ve Zr) zenginleşmiş yönelim sunar. Kapadokya Bölgesindeki petrografik ve tüm kayaç jeokimya sonuçları bütün magmatik kayaçların yitim magmatizması ile geliştiğine ve A-tipi plütona doğru alt kıta kabuğu ve litosferik manto katkısının arttığına işaret etmektedir.

Anahtar kelimeler: Kapadokya plütonik kayaçları, Orta Anadolu, jeokimya, petrografi

Abstract: In the Cappadocia region, the Bayramhacı, İdişdă̆l, Göynük, Karadăg, Yeşilöz, Akçataşs plutonic and/or subvolcanic rocks exposing in the northern part of the Nevşehir province and Acigöl plutonic rocks cropping out at the south are included to the Central Anatolian Granitoids. The Akçatas pluton, exposing at the south of Nevşehir, has monzogranite composition and rarely contain mafic microgranular enclave (MME) and K.feldspar megacrysts. Magmatic rocks in the northern section have quite different compositions varying from monzogranite to quartz

*Yazışma / Correspondence: ayse.orhan@nevsehir.edu.tr

(C) 2018 JMO Her hakkı saklıdır/All rights reserved http://tjb.jmo.org.tr http://dergipark.gov.tr/tjb 
monzonit / monzodiorite - monzonite - phonolitic tephrite / tephritic phonolite. Quartz monzonitic / monzodioritic rocks dominantly contain MME and large K.feldspar megacrysts. Monzonitic rocks are in contact with the porphyritic subvolcanic rocks which contain K-feldspar or leucite megacrysts.

The monzogranitic rocks in the region are of subalkaline, high-K series calc-alkaline character and I-type leucogranite. Quartz monzonite, monzonite / monzodioritic rocks show compositions of subalkaline, high-K calc-alkaline to shoshonitic with I-type melt character. Monzonitic and phonolitic tephrite / tephritic phonolite rocks exhibit yield A-type melt characteristics with alkaline and shoshonitic composition. Magmatic rocks with different compositions present different trace element abundance. Light rare element (LREE) enrichment ratios tend to increase from monzogranite $\left((\mathrm{La} / \mathrm{Yb})_{n}=4.58-12.11\right)$ to quartz monzonite / monzodiorite $\left((\mathrm{La} / \mathrm{Yb})_{n}=12.06-33.78\right)$ and monzonite and phonolitic tephrite / tephritic phonolite rocks $\left((\mathrm{La} / \mathrm{Yb})_{n}=23.29-82.17\right)$. In Ocean ridge granite normalized element diagrams, all magmatic rocks show large ion lithophile elements (LILE: $K, R b, B a$ ) enrichment with respect to high field strength elements (HFSE: Ta, Nb, Hf, Zr, Y) indicating that they were formed in a subduction zone and/ or collisional tectonic setting. However, alkaline magmatic rocks are represented by significant $L I L(K, R b, B a, T h)$ and HFS ( $\mathrm{Ta}, \mathrm{Nb}, \mathrm{Ce}$ and $\mathrm{Zr}$ ) enrichment compared to calc-alkaline magmatic rocks. The petrographic and wholerock chemistry data from the Cappadocia Region indicate that studied magmatic rocks were formed by subductionzone magmatism and the contribution from subcontinental lithospheric mantle is much noticeable for the A-type plutons.

Keywords: Cappadocia plutonic rocks, Central Anatolia, geochemistry, petrography

\section{GíRiş}

Coğrafik olarak batıda Tuz Gölü fayı, doğuda Ecemiş fayı ve kuzeyde İzmir-Ankara-Erzincan Sütur zonu ile sinırlanan bölge Orta Anadolu Kristalen Karmaşığı olarak tanımlanır (Erkan, 1976; Göncüoğlu vd., 1991). OAKK içerisinde irili ufaklı birçok granitoyid, batolit ve stoklar halinde yüzeylenmektedir (Şekil 1). Yapılan petrolojik çalışmalar ile Üst Kretase - Alt Tersiyer zaman aralığında üç farklı bileşim sergileyen plütonik intrüzyonların üç evrede geliştiği ileri sürülmüştür (Akıman vd., 1993; Ekici, 1997; Ekici ve Boztuğ, 1997; Aydın vd. 1998; Boztuğ, 1998; Aydın vd., 2001; İlbeyli vd., 2004; Tatar ve Boztuğ, 2005; Kadıoğlu vd., 2006; Köksal ve Göncüoğlu, 2008).
Bu magmatik kayaçlar;

(1) Erken granit evresini temsil eden yüksek-K, kalk-alkalen ve S-tipi (syn-COLG) ve I-S tipi löko-granitler (veya C-tipi) (Yozgat Batoliti, Ağaçören ve Ekecikdağı Granitoyidinin alt birimleri),

(2) Çarpışma sonrası (post-COLG) gelişmiş alt kıta kabuğu ve manto kaynaklı malzemeden türemiş, mafik mikroganular anklav (MME) ve iri-K-feldispat içeren, yüksek-K ve şoşonitik, kalk-alkalen ve I-tipi (veya H-tipi) plütonlar (Behrekdăg, Çelebi, Cefelikdağ, Yozgat, Ağaçören, Barandağ, Ekecikdağ ve Terlemez Granitoyidi) ve,

(3) Çarpışmanın son evresini temsil eden ve/ veya kıta içi (WPG) gelişmiş A-tipi, alkalen, silisce doygun monzonitik - siyenitik plütonlar (İdişdağ1, Hamit, Eğrialan ve Barandağ Granitoyidi) veya silis bakımından tüketilmiş nefelinli-nozeyanlı siyenit porfir (Atdere Granitoyidi) plütonlardır. 


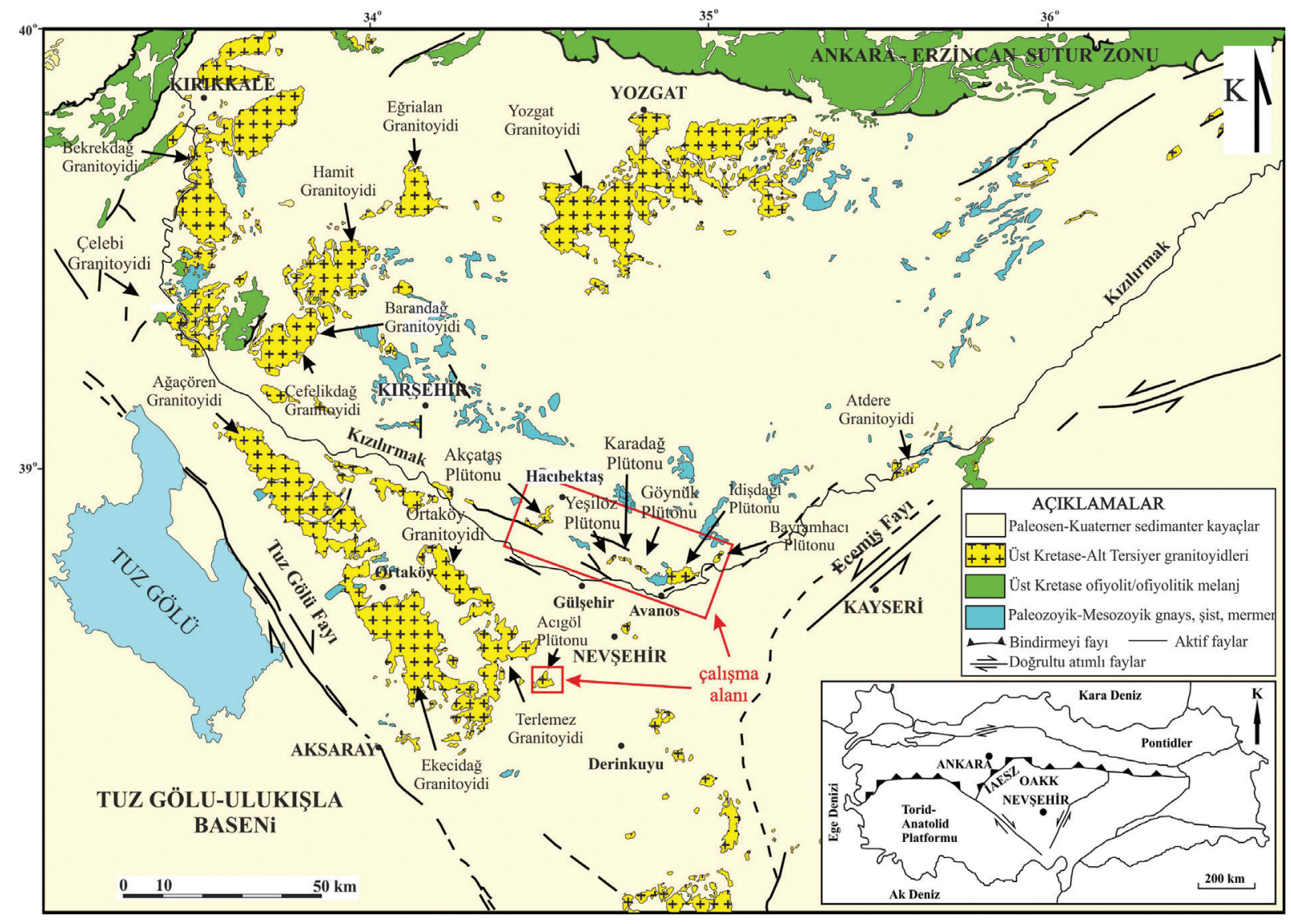

Şekil 1. Orta Anadolu Kristalen Karmaşığının jeolojik ve çalışma alanı yer bulduru haritası (MTA, 2005'den sadeleştirilerek alınmıştır).

Figure 1. Geological and location map of the study area within the Central Anatolia Crystalline Complex (simplified from MTA, 2005).

Kapadokya (Nevşehir) bölgesinde ender yüzlek veren Üst Kretase yaşlı plütonik ve/veya subvolkanik kayaçlar (Bayramhac1, İdişdağ1, Göynük, Karadağ, Yeşilöz, Akçataş ve Acıgöl plütonları) Orta Anadolu Kristalen Karmaşığ1 içerisinde stoklar şeklinde yüzeylemektedir (Şekil 1). Bölgede önceki yıllarda jeolojik (Becker, 1956; Aydın, 1984; Atabey vd., 1988; Atabey, 1989; Aydın, 1991; Dönmez vd., 2005; Orhan ve Demirbilek, 2012) ve plütonik/subvolkanik kayaçların petrojenezi (Köksal, 1996; Aydın vd., 1988; Köksal vd., 2001; Kadıŏglu vd., 2006) ve yaşlandırmasına (Kadığlu vd., 2006; Aydar vd., 2012) yönelik çeşitli araştırmalar gerçekleştirilmiştir. Akçataş Plütonunun jeolojik ve petrografik özellikleri ilk olarak Aydın (1984; 1991) tarafindan belirlenmiştir. Aynı araştırmacı tarafindan plütonda MME ve bu kayaçları farklı doğrultularda kesen damar kayaçların varlığından bahsedilmiş ve plütonun granit - kuvars monzonit bileşimli olduğu tespit edilmiştir. Köksal (1996) tarafından İdişdağı siyenitoyidini kesen Karahıdır volkaniklerinin jeokimyasal verilere göre İdişdağ1 siyenitoyidinin subvolkanik eşleniği olduğu tespit edilmiştir. İdişdağı plütonundayapılmış petrografik ve jeokimyasal çalışmalar ile silis bakımından aşırı doygun/doygun monzonitik - siyenitik kayaçlar ve silis bakımından tüketilmiş siyenitik 
bileşimli kayaçlardan oluştuğu belirlenmiştir. (Köksal, 1996; Aydın vd., 1998; Köksal vd., 2001; Kadıŏlu vd., 2006). Aynı araştırmacılar tarafından plütonun çarpışma sonrası gelişmiş alt kıta kabuğu ve manto kaynaklı malzemeden türemiş A-tipi plütonları temsil ettiği ileri sürülmüştür. Kadıŏglu vd. (2006) tarafından İdişdağı Plütonunu da kapsayan çalışmada siyenitik alkalin kayaçların amfibollerinden yapılan yaşlandırmada Ar-Ar yaşı 69.8 \pm 0.3 My olarak tespit edilmiştir. Nevşehir'in güneyinde çalışma alanının temelini oluşturan Acıgöl Plütonunun petrojeneziyle ilgili çalışma bulunmamasına rağmen Aydar vd., 2012'de yaptıkları çalışma ile bu plütonun yaşını $\mathrm{Ar} / \mathrm{Ar}$ ve $\mathrm{Pb} / \mathrm{U}$ yöntemiyle $78.44 \pm 0.29 \mathrm{My}$ ve $77.8 \pm 4.4$ My olarak belirlemişlerdir. Benzer şekilde Nevşehir'in kuzeyinde yüzeyleyen Bayramhac1, Göynük, Karadağ plütonik ve/veya subvolkanik kayaçlarında gerçekleştirilmiş herhangi bir petrografik ve jeokimyasal çalışma mevcut değildir. Kapadokya (Nevşehir) bölgesinde kalkalkalen ve alkalen karakterli magmatik kayaçların yüzeylediği aşikardır. Ancak, bölgede yüzeyleyen Üst Kretase - Alt Tersiyer yaşı magmatik kayaçların petrografik ve jeokimyasal özelliklerini ortaya koyan detaylı bir çalışmanın yapılmadığ 1 gözlenmektedir. $\mathrm{Bu}$ çalışmanın amacını Kapadokya (Nevşehir) bölgesinde yüzeyleyen plütonik ve/veya subvolkanik kayaçların petrografik ve jeokimyasal özelliklerini ortaya koymak oluşturmaktadır. Bölgedeki Üst Kretase Alt Tersiyer yaşlı magmatik kayaçların petrografik ve jeokimyasal özellikleri Orta Anadolu'daki diğer plütonik kayaçlarla eşleştirerek petrojenetik süreçleri ortaya konulmuş ve literatürdeki eksiklikler giderilmiştir.

\section{GENEL JEOLOJI}

Çalışma alanı Orta Anadolu Kristalen Karmaşı içerisinde yer almaktadır (Şekil 1). Orta Anadolu Kristalen Karmaşığında dört farklı birim topluluğu tanımlanmıştır (Göncüoğlu vd., 1991; Erler vd., 1996). Bunlar alttan üste doğru Orta Anadolu metamorfitleri, ofiyolitik melanj ve/veya ofiyolit, Orta Anadolu granitoyidleri ve Tersiyer yaşlı sedimanter ve volkanik örtü birimleri şeklindedir (Şekil 1). Çalışma alanının kuzeyinde Orta Anadolu Metamorfitlerinin üst seviyelerine ait PaleozoyikMesozoyik yaşlı Bolçadağ Formasyonu, Orta Anadolu magmatiklerine ait Üst Kretase yaşlı plütonik ve/veya subvolkanik kayaçlar ve Tersiyer sedimanter ve volkanik birimler yüzeyler (Şekil 2). Güneyde ise Üst Kretase plütonik ve bazik kayaçlar ile bunların üzerini örten Üst MiyosenKuvaterner yaşlı sedimanter ve volkanik kayaçlar yüzeylenmektedir (Şekil 3).

Bolçadağ Formasyonu kalk şist ve mermerlerden oluşur (Seymen, 1981; Atabey, 1989; Köksal, 1996; Orhan ve Demirbilek, 2012). Bölgede Akçataş ve İdişdağı plütonları Bolçadağ Formasyonunu keserek yerleşen önemli iki intrüzif kütledir. Köksal (1996) tarafından İdişdağı Plütonu ile metamorfikler arasındaki dokanakta Ca granat + amfibol + kalsit + kuvars mineral parajenezi ile orta dereceli kontakt metamorfizmayı karakterize eden hornblend-hornfels fasiyesi koşulları tanımlanmıştır.

Nevşehir güneyinin önemli magmatik kütlesi olan Acıgöl plütonu (Şekil 3) gri-açık gri renklerde gözlenmektedir. Plütonik kayaç orta-kaba taneli holokristalin dokuda olup nadiren K-feldispat megakristallerinin varlığından dolayı porfirik doku özelliği kazanmıştır (Şekil 4a). Plütonda keskin dokanaklı elipsoidal-yuvarlağımsı nadir mafik mikrogranüler anklavların yanısıra, plütonun aplit ve pegmatitik damarlar tarafindan kesildiği gözlenmektedir. 


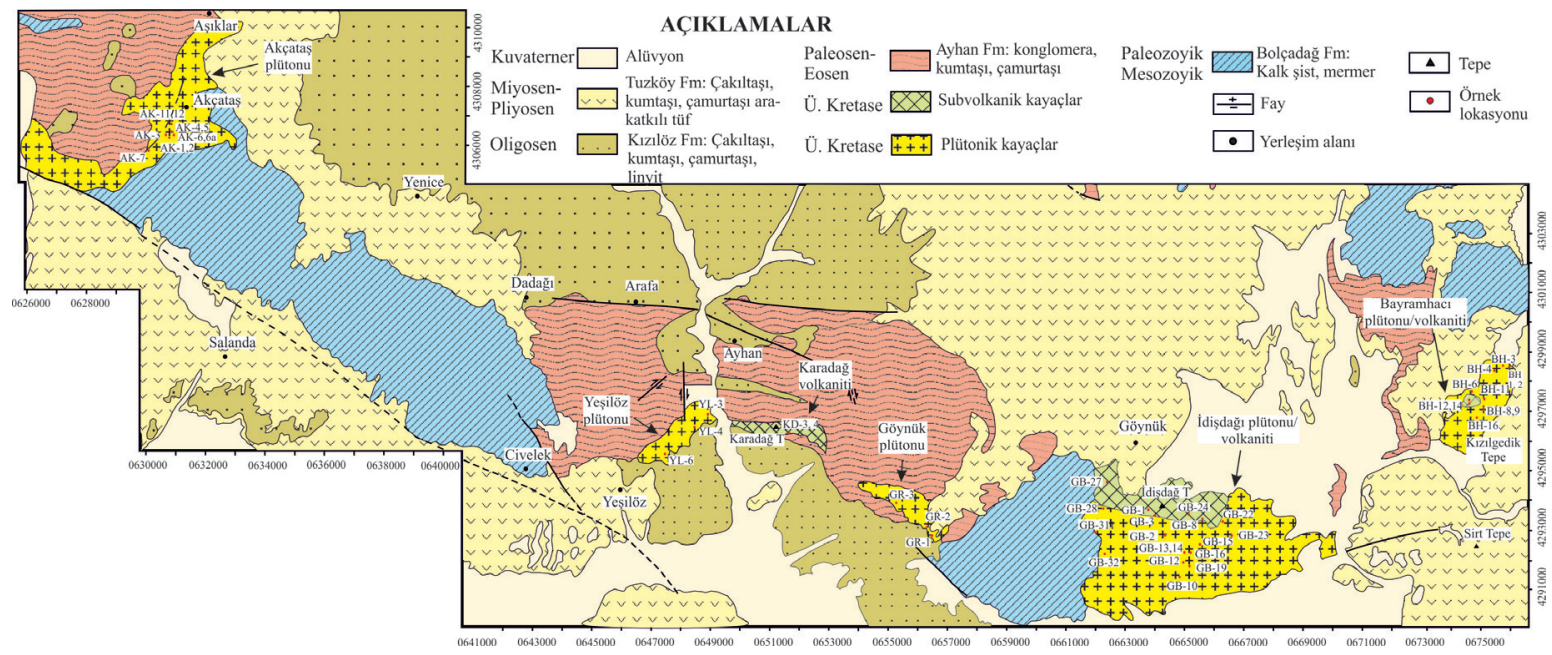

Şekil 2. Nevşehir kuzeyinin jeolojik ve örnek lokasyon haritası (MTA, 2001'den sadeleştirilerek alınmıştır).

Figure 2. Geological map of northern Nevşehir and the sample locations (simplified from MTA, 2001).

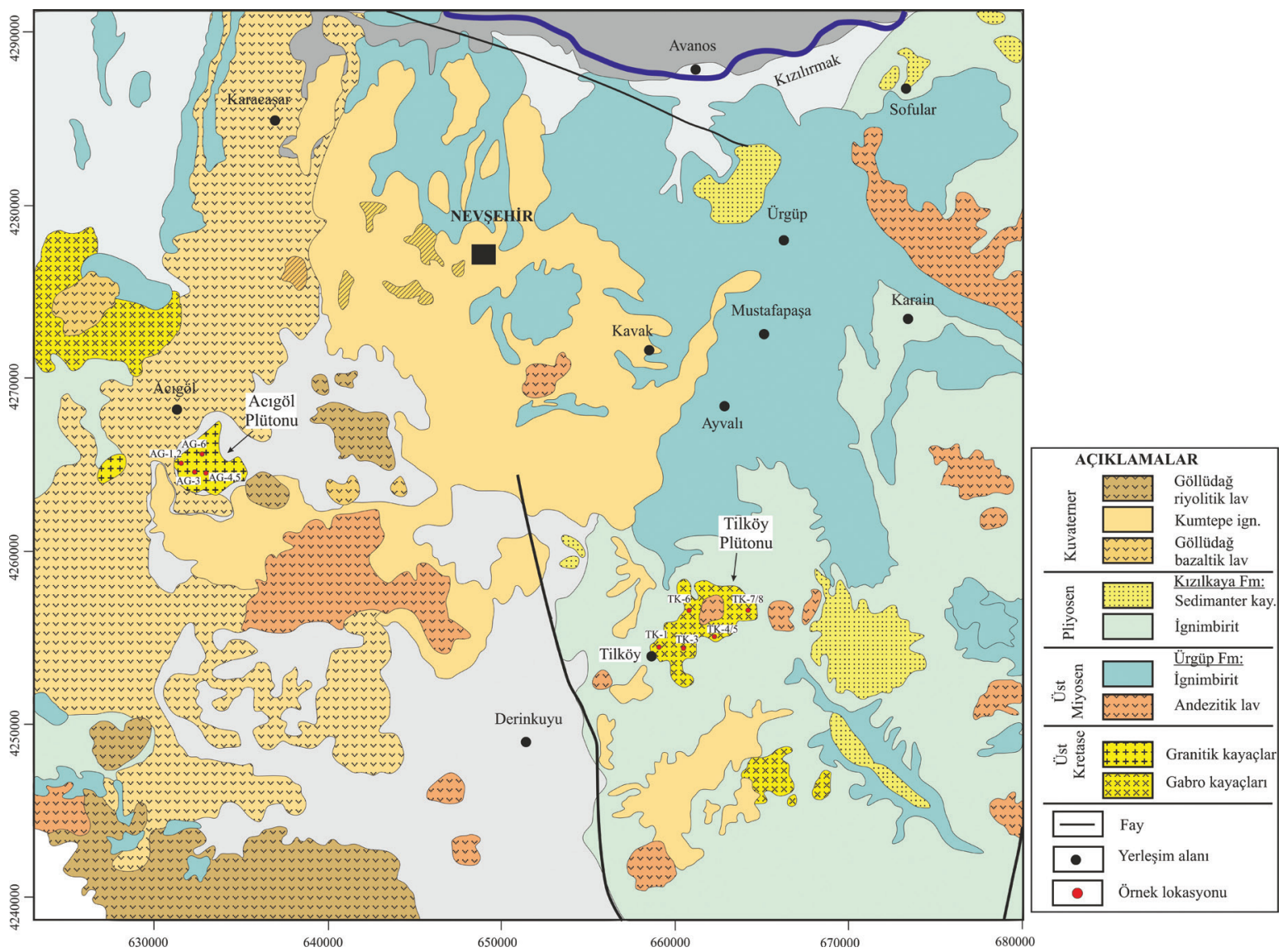

Şekil 3. Nevşehir güneyinin jeolojik ve örnek lokasyon haritası (jeoloji haritası Aydar vd., 2012'den alınmıştır).

Figure 3. Geological map of southern Nevşehir and the sample locations (geology map is taken from Aydar et al., 2012). 
Nevşehir'in kuzeyinde batıdan doğuya doğru oldukça altere küçük stoklar halinde yüzeyleyen Akçataş, Yeşilöz, Karadağ, Göynük, İdişdağı ve Bayramhac1 plütonik/subvolkanik kayaçlarının (Şekil 2) ayrışım renklerinin gri ile pembe renk tonlarında değiştiği gözlenmektedir. Plütonik kayaçlar ince-orta ve kaba taneli holokristalin dokuya sahiptir. İdişdağı ve Akçataş plütonları elipsoidal ve düzensiz geometrik şekillerde değişik boyutlarda magma mingling ürünleri olan MME içerirler (Şekil 4b, c). Yer yer iri K-feldispat megakristallerinin varlığı nedeniyle Akçataş plütonuna porfirik doku özelliği veren iri K-feldispat megakristalleri İdişdağ gözlenmemektedir. Bayramhacı ve İdişdağı plütonları ise muhtemel kendi magmasının ürünleri olan subvolkanik kayaçlar ile dokanak halindedir. Subvolkanik kayaçlar ise iri K-feldispat megakristalleri ve/veya lösit kristallerinin varlı̆̆ ile porfirik doku özelliği kazanmıştır (Şekil 4d, e, f). Bütün plütonik kayaçlar kendi magmasının geç ürünleri olan damar kayaçları tarafından farklı doğrultularda kesilmiştir. Aplit dayklar ince taneli holokristalin dokuda gözlenir.

\section{MATERYAL VE YÖNTEM}

Nevşehir'in kuzeyi ve güneyinde yüzeyleyen plütonik kayaçlardan toplam 80 adet örneğin ince kesitleri MTA Genel Müdürlüğünde ve 37 adet örneğin ana, iz ve nadir toprak element analizleri
ACME (Kanada) analitik laboratuarlarında gerçekleştirilmiştir. Analizleri gerçekleştirilen kayaç örneklerinin lokasyonları Şekil 2 ve 3'de verilmiştir. Ana oksit, iz ve nadir toprak elementleri analizi için yaklaşı 100 gr taze örnek alterasyon kısımları temizlenerek analize hazır hale getirilmiştir. Ana elementler ve bazı iz elementler (Ba, Ni, Sr, Sc, Y ve Zr) ICP-ES, iz ve nadir toprak elementler ise ICP-MS ile analiz edilmiştir. Element konsantrasyonları CANMET SY-4 ve STD SO-17 standartlarına göre belirlenmiştir. Ana ve iz elementlerin doğruluk payları sirasiyla \% 0.001-0.04 ve 0.01-0.5 ppm arasında değişmektedir.

\section{MINERALOJIK VE PETROGRAFIK İNCELEME}

Bölgede yüzeyleyen plütonik ve subvolkanik kayaçlarda gerçekleştirilmiş mineralojik ve petrografik tanımlamalar Çizelge 1'de verilmiştir. Kayaçların sınıflandırılması ise tüm kayaç ana element jeokimyasından hesaplanmış CIPWnormları kullanılarak Streckesien (1976) diyagramında yapılmıştır (Çizelge 2; Şekil 5). Yapılan incelemelere göre bölgedeki kayaçlar, monzogranit (kuvars bolluğu yüksek) kuvars monzonit/kuvars monzodiyorit (kuvars bolluğu orta) ve monzonit (kuvars bolluğu düşük) / fonolitik tefrit ve tefritik fonolit (kuvars içermeyen) olarak üç farklı bileşimde tanımlanmıştır. 

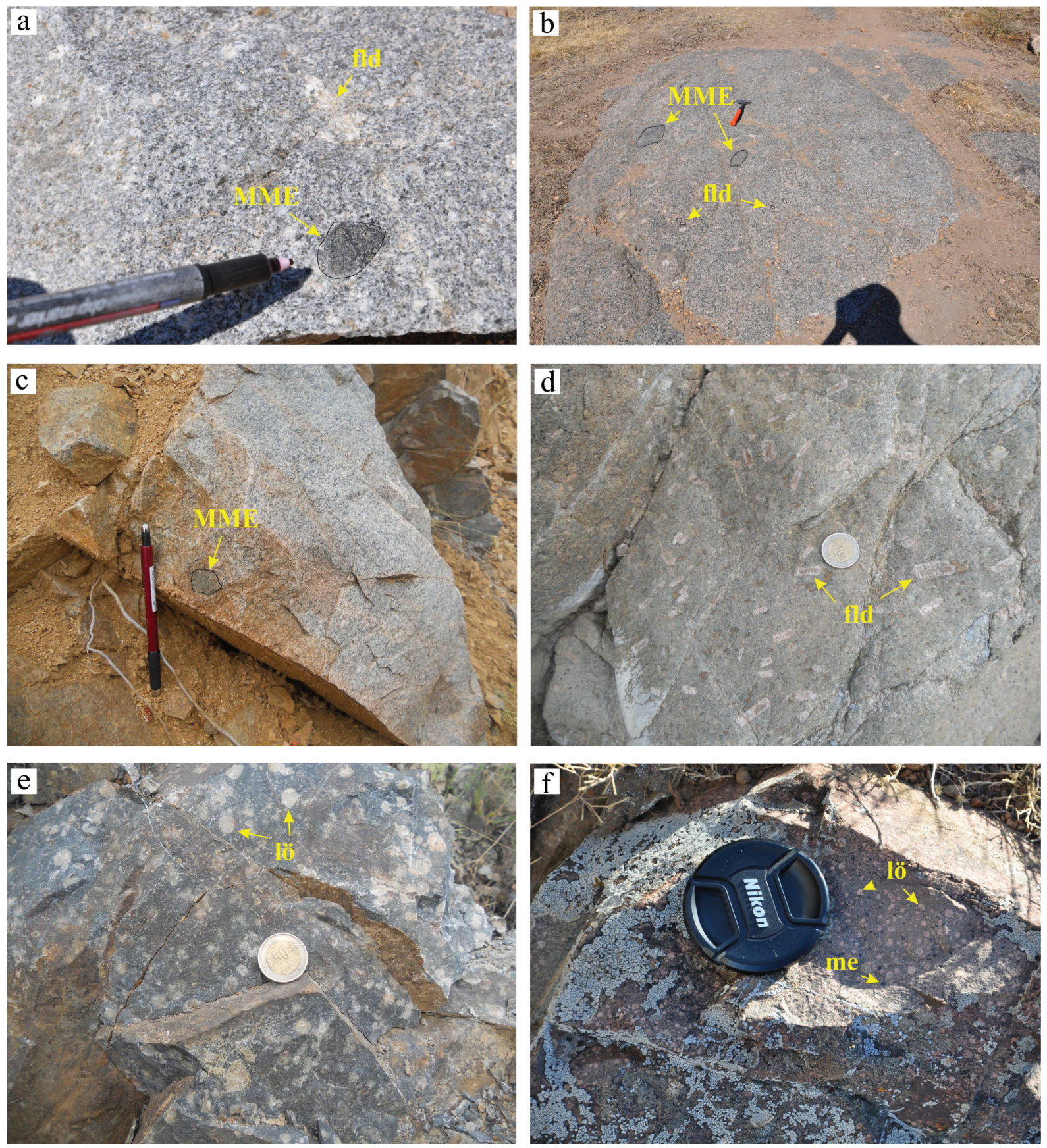

Şekil 4. (a) Acıgöl (AG-4 ve 5), (b) Akçataş (AK-11, 12) ve (c) İdişdağı plütonu (GB-10), porfirik dokulu, (d, e) İdişdağı (GB-3 ve GB-8) ve (f) Bayramhacı (BH-14) subvolkanik kayaçların arazi görüntüsü (fld; feldispat, MME; mafik mikrogronülar anklav, lö; lösit, me; melanit).

Figure 4. Field photography from the (a) Acıgöl (AG-4 and 5), (b) Akçataş $(A K-11,12)$ and (c) İdişdăgl pluton (GB-10), porphyritic texture from (d, e) İdişdağ l (GB-3 and GB-8) and (d) Bayramhacl (BH-14) subvolcanites (Fld; feldspar; MME; mafic microgranular enclave, lö; leucite; me; melanite). 
Çizelge 1. Kapadokya (Nevşehir) Bölgesi plütonik, subvolkanik ve damar kayaç örneklerinin mikroskobik incelenmesi.

Table 1. Microscopical study of plutonic, subvolcanic and vein rock samples from the Cappadocia (Nevşehir) Region.

\begin{tabular}{|c|c|c|c|c|}
\hline Plütonik kayaç & Kayaç tipi & Doku & Mineralojik bileşim & Kayaç adı \\
\hline \multirow{2}{*}{$\begin{array}{l}\text { Bayramhacı } \\
\text { plütonu }\end{array}$} & ana kayaç & $\begin{array}{l}\text { ince-orta taneli } \\
\text { hipidiyomorfik }\end{array}$ & $\begin{array}{l}\mathrm{q}+\mathrm{kfl}+\mathrm{amf}+\mathrm{plj} \pm \mathrm{bi} \pm \mathrm{pr} \pm \mathrm{ti} \pm \mathrm{ap} \pm \mathrm{op} \pm \mathrm{sr} \pm \mathrm{kl} \\
\mathrm{kfl}+\mathrm{plj}+\mathrm{amf}+\mathrm{pr} \pm \mathrm{q} \pm \pm \mathrm{op} \pm \mathrm{sr} \pm \mathrm{ka} \pm \mathrm{ko} \pm \mathrm{kl}\end{array}$ & $\begin{array}{l}\text { Tonalit, } \\
\text { monzonit }\end{array}$ \\
\hline & subvolkanik & $\begin{array}{l}\text { porfirik } \\
\text { hipokristalin }\end{array}$ & $\begin{array}{l}\mathrm{kfl}+\mathrm{plj}+\mathrm{amf}+\mathrm{pr} \pm \mathrm{q} \pm \pm \mathrm{op} \pm \mathrm{sr} \pm \mathrm{ka} \pm \mathrm{ko} \pm \mathrm{kl} \\
\mathrm{kfl}+\mathrm{nf}+\mathrm{nö} \pm \mathrm{me} \pm \mathrm{op} \pm \mathrm{ka} \pm \mathrm{ko} \pm \mathrm{kl}\end{array}$ & $\begin{array}{l}\text { kuvars latit, } \\
\text { tefritik fonolit }\end{array}$ \\
\hline \multirow{3}{*}{ İdiş̧ağ 1} & ana kayaç & $\begin{array}{l}\text { ince-orta taneli } \\
\text { hipidiyomorfik }\end{array}$ & $\begin{array}{l}\mathrm{q}+\mathrm{plj}+\mathrm{kfl}+\mathrm{bi} \pm \mathrm{amf} \pm \mathrm{ep} \pm \mathrm{ti} \pm \mathrm{op} \pm \mathrm{sr} \\
\mathrm{kfl}+\mathrm{plj}+\mathrm{amf}+\mathrm{pr} \pm \mathrm{q} \pm \mathrm{ep} \\
\pm \mathrm{ti} \pm \mathrm{ks} \pm \mathrm{op} \pm \mathrm{sr} \pm \mathrm{ka} \pm \mathrm{ko}\end{array}$ & $\begin{array}{l}\text { monzo granit - } \\
\text { kuvars monzonit, } \\
\text { monzonit }\end{array}$ \\
\hline & subvolkanik & $\begin{array}{l}\text { porfirik } \\
\text { hipokristalin }\end{array}$ & $\begin{array}{l}\mathrm{kfl}+\mathrm{plj}+\mathrm{q}+\mathrm{amf} \pm \mathrm{pir} \pm \\
\mathrm{ep} \pm \mathrm{ti} \pm \mathrm{op} \pm \mathrm{sr} \pm \mathrm{ka} \pm \mathrm{kl} \pm \mathrm{ko} \\
\mathrm{kfl} \pm \mathrm{nf}+\mathrm{lö}+\mathrm{pr} \pm \mathrm{op} \pm \mathrm{ka}\end{array}$ & $\begin{array}{l}\text { kuvars latit, } \\
\text { fonolitik tefrit - } \\
\text { tefritik fonolit }\end{array}$ \\
\hline & damar kayacı & $\begin{array}{l}\text { porfirik } \\
\text { hipokristalin }\end{array}$ & $\mathrm{nf}+\mathrm{me}+\mathrm{pr} \pm \mathrm{op}$ & fonolitik tefrit \\
\hline Göynük & ana kayaç & $\begin{array}{l}\text { kaba taneli } \\
\text { hipidiyomorfik }\end{array}$ & $\begin{array}{l}\text { plj+kfl }+\mathrm{q}+\mathrm{amf} \pm \mathrm{bi} \pm \\
\text { ti } \pm \mathrm{ap} \pm \mathrm{op} \pm \mathrm{kl} \pm \mathrm{sr} \pm \mathrm{ka}\end{array}$ & $\begin{array}{l}\text { monzogranit - } \\
\text { kuvars monzonit }\end{array}$ \\
\hline Karadağ & ana kayaç & $\begin{array}{l}\text { porfirik } \\
\text { hipokristalin }\end{array}$ & $\begin{array}{l}\mathrm{q}+\mathrm{plj}+\mathrm{kfl}+\mathrm{bi}+\mathrm{amf} \pm \\
\mathrm{ti} \pm \mathrm{ap} \pm \mathrm{op} \pm \mathrm{kl} \pm \mathrm{sr} \pm \mathrm{ka}\end{array}$ & riyolit \\
\hline Yeşilöz & ana kayaç & $\begin{array}{l}\text { orta-kaba taneli } \\
\text { holokristalin }\end{array}$ & $\begin{array}{l}\mathrm{kfl}+\mathrm{plj}+\mathrm{q}+\mathrm{amf} \pm \mathrm{pr} \pm \\
\mathrm{ti} \pm \mathrm{ap} \pm \mathrm{op} \pm \mathrm{sr} \pm \mathrm{ka}\end{array}$ & kuvars monzonit \\
\hline \multirow{3}{*}{ Akçataş } & ana kayaç & $\begin{array}{l}\text { orta-kaba taneli } \\
\text { hipidiyomorfik }\end{array}$ & $\mathrm{plj}+\mathrm{kfl}+\mathrm{q}+\mathrm{amf} \pm \mathrm{bi} \pm \mathrm{pr} \pm \mathrm{ti} \pm \mathrm{ap} \pm \mathrm{op} \pm \mathrm{kl} \pm \mathrm{sr}$ & $\begin{array}{l}\text { kuvars } \\
\text { monzodiyorit }\end{array}$ \\
\hline & MME & $\begin{array}{l}\text { ince taneli } \\
\text { hipidiyomorfik }\end{array}$ & $\begin{array}{l}\mathrm{plj}+\mathrm{kfl}+\mathrm{amf} \pm \mathrm{bi} \pm \mathrm{q} \pm \\
\mathrm{pr} \pm \mathrm{ti} \pm \mathrm{ap} \pm \mathrm{op}\end{array}$ & monzodiyorit \\
\hline & aplit & $\begin{array}{l}\text { ince taneli } \\
\text { hipidiyomorfik }\end{array}$ & $q+p l j+k f l+b i$ & monzogranit \\
\hline \multirow{2}{*}{ Acigöl } & ana kayaç & $\begin{array}{l}\text { orta-kaba taneli } \\
\text { hipidiyomorfik }\end{array}$ & $\begin{array}{l}\mathrm{q}+\mathrm{plj}+\mathrm{kfl}+\mathrm{bi} \pm \mathrm{amf} \pm \\
\text { ti } \pm \mathrm{ap} \pm \mathrm{op} \pm \mathrm{kl} \pm \mathrm{sr}\end{array}$ & monzogranit \\
\hline & MME & $\begin{array}{l}\text { ince taneli } \\
\text { hipidiyomorfik }\end{array}$ & $\mathrm{plj}+\mathrm{kfl}+\mathrm{amf} \pm \mathrm{q} \pm \mathrm{ti} \pm \mathrm{ap} \pm \mathrm{op}$ & $\begin{array}{l}\text { kuvars } \\
\text { monzodiyorit }\end{array}$ \\
\hline
\end{tabular}

amf; amfibol, ap; apatit,bio; biyotit, ep; epidot, ka; kalsit, kfl; K-feldispat, kl; klorit, ko; kaolinit, ks; ksenotim, lö; lösit, me; melanit, nf; nefelin, op; opak, q; kuvars, plj; plajiyoklaz, pr; piroken, sr; serisit, ti; titanit. 


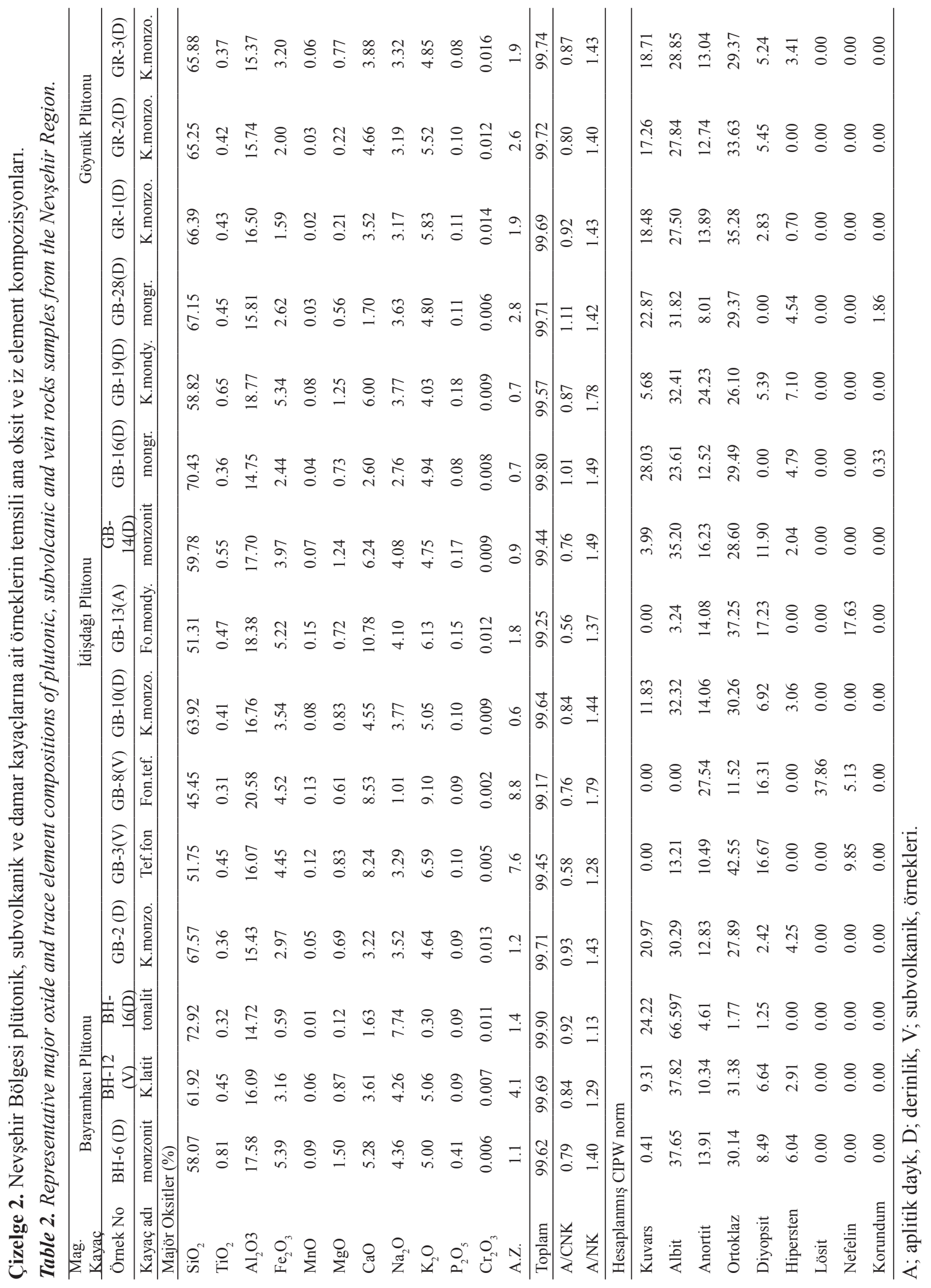




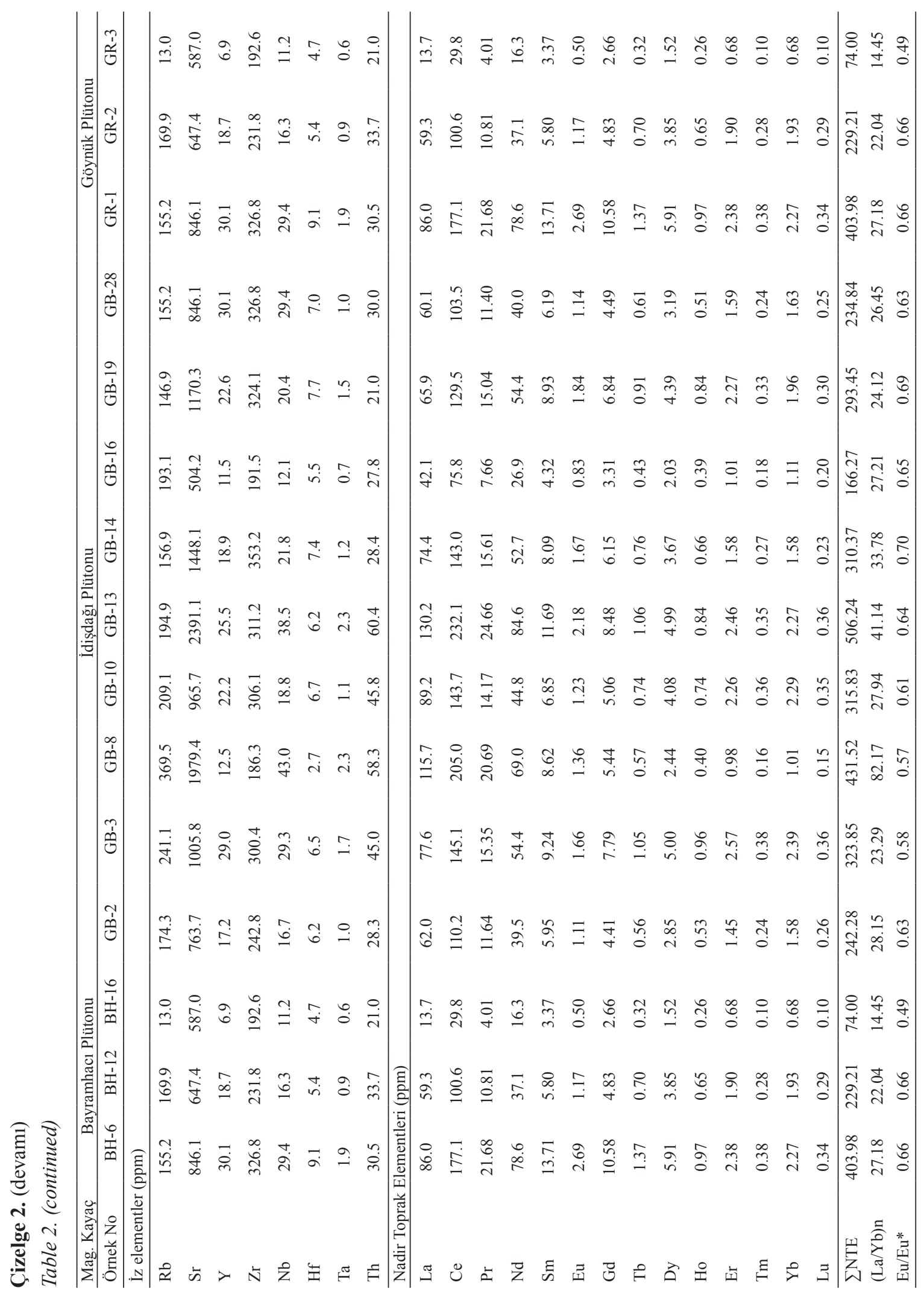




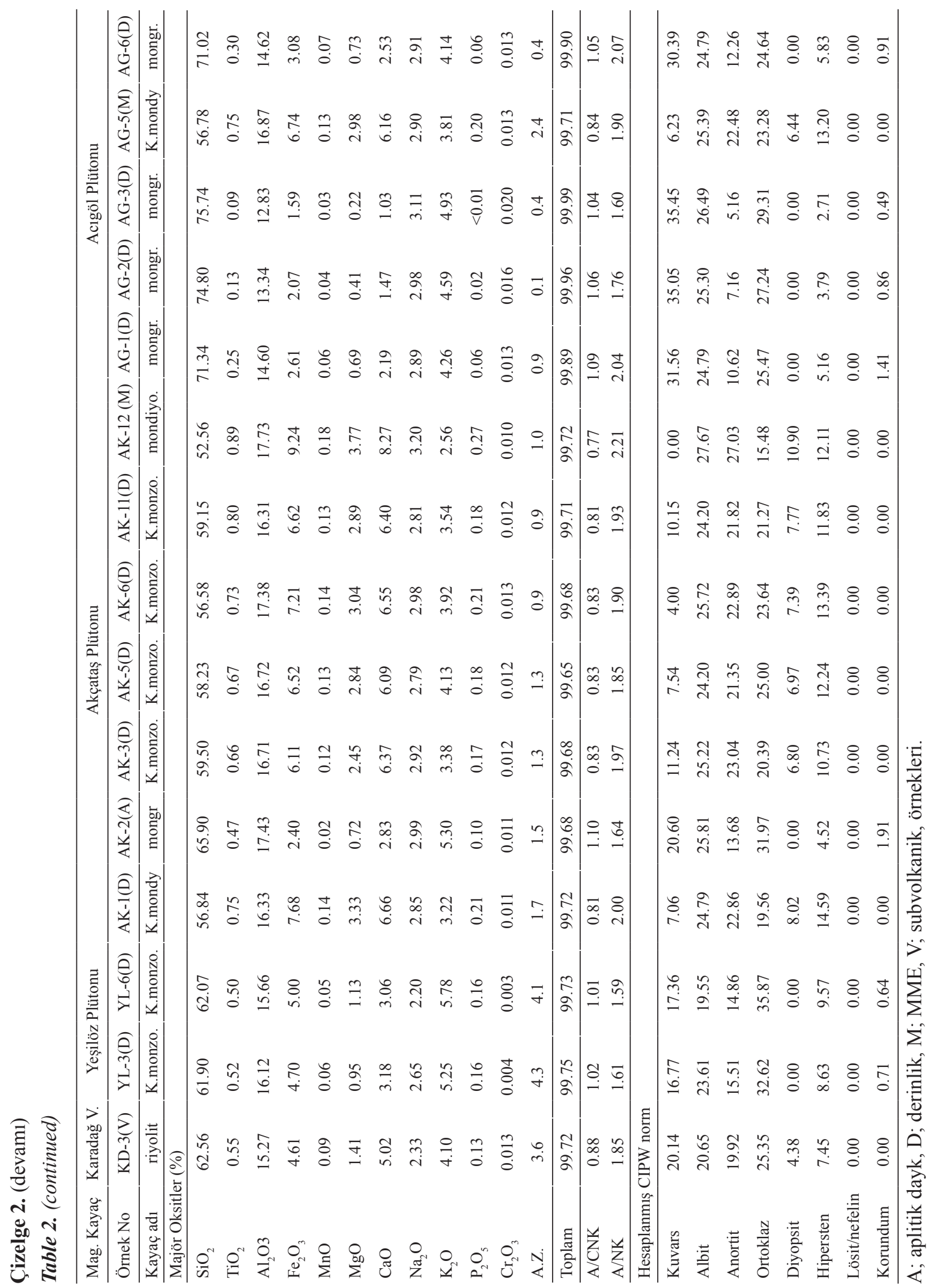




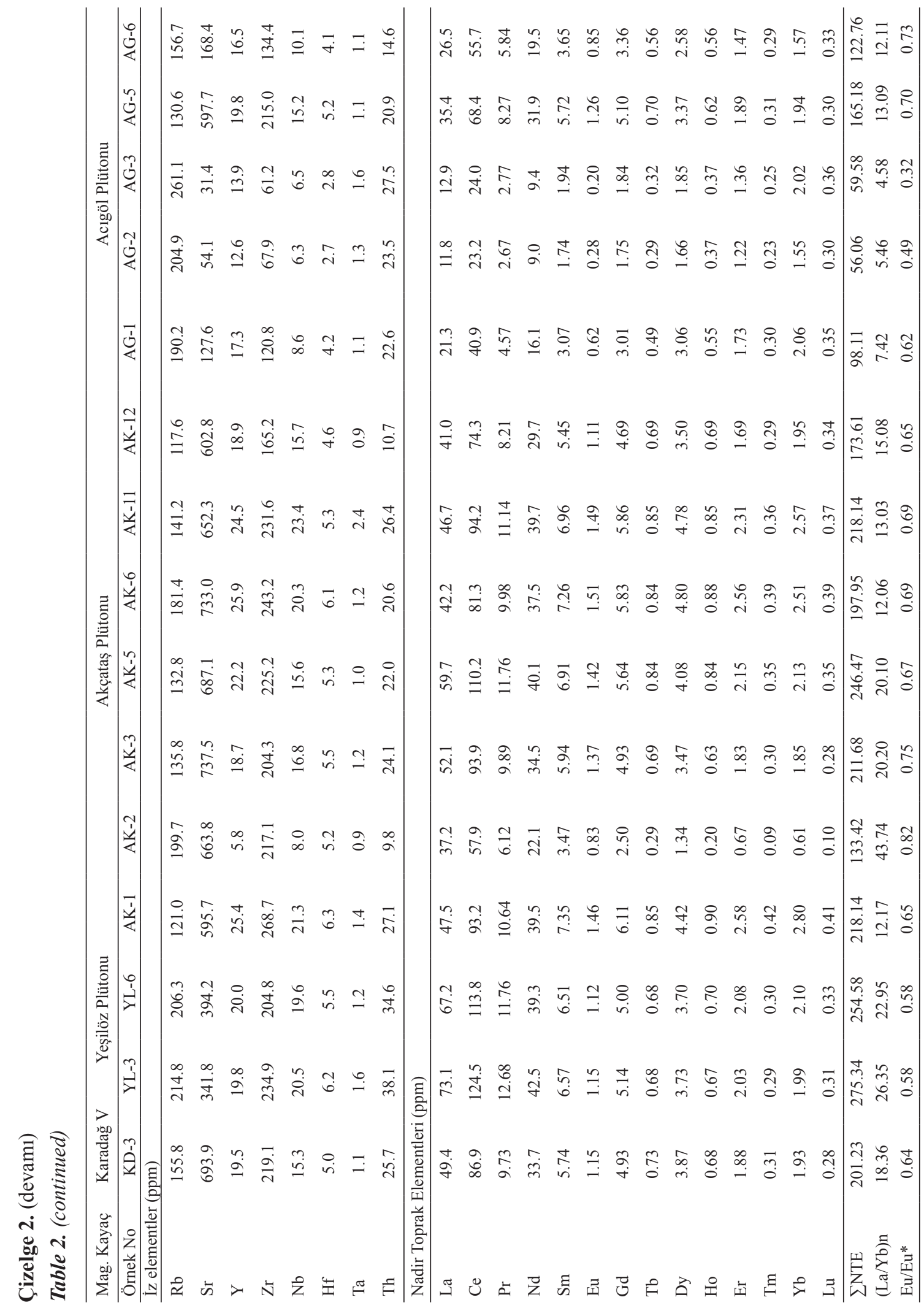




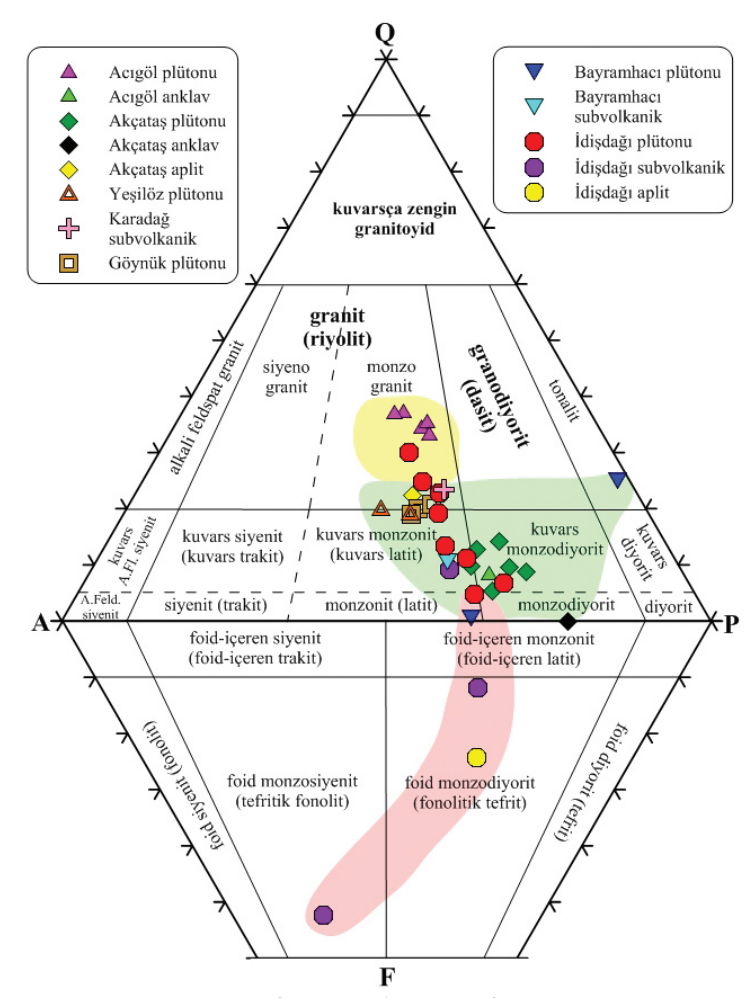

Şekil 5. Nevşehir bölgesi plütonik ve subvolkanik kayaçların CIPW-normlarına göre QAPF (kuvars, A. feldispat, plajiyoklaz, foid) diyagramında sinıflandırılması (Streckeisen, 1976).

Figure 5. Based on CIPW-norm QAPF (quartz, A. feldspar, plagioclase, foid) classification of the Nevşehir region plutonic and subvolcanic rocks (Streckeisen, 1976).

Acıgöl plütonu ve anklav örneği monzogranit ve kuvars monzodiyorit; Akçataş plütonu, anklav ve aplitik dayk örnekleri kuvars monzodiyorit, monzodiyorit ve monzogranit; Göynük ve Yeşilöz plütonları kuvars monzonit ve Karadağ subvolkaniti riyolit bileşimlerine sahiptir. İdişdağ1 ve Bayramhacı plütonik/subvolkanik kayaçları ise kuvars içeriğine göre oldukça farklı bileşimler sergilemektedir. İdişdağı plütonuna ait bazı örneklerin (GB-16 ve GB-28) kuvars bolluğu yüksek olup monzogranit bazı örnekleri ise kuvars bolluğu orta/düşük olup kuvars monzonit, kuvars monzodiyorit ve monzonit bileşimine sahiptir. İdişdağ1 subvolkanik ve aplitik dayk örnekleri ise kuvars içermeyen (foid içeren) kayaç grubunda yer almakta ve tefritik fonolit, fonolitik tefrit ve foid monzodiyorit bileşimleri sunmaktadır (Şekil 5). Benzer şekilde Bayramhacı plütonunun kuvars bolluğu değişken olup tonalit ve monzonit, subvolkanit eşleniği ise kuvars latit bileşimindedir. Bayramhac1 subvolkanik (BH-14 nolu örnek) kütleye ait tüm kayaç jeokimya analiz sonucu bulunmaması nedeniyle, İdişdağ 1 subvolkanik kütleye ait GB-8 nolu örnek ile benzer bileşim sergilemesinden dolayı fonolitik tefrit olarak adlandırılmıştır (Çizelge 1).

Acıgöl, Akçataş, Yeşilöz ve Göynük plütonları orta-kaba taneli hipidiyomorfik doku sunarken (Şekil 6a, b, d), Karadă̆ subvolkanik kayacı hipokristalin porfirik dokudadır (Şekil 6e). Plütonik ve subvolkanik kayaçlar benzer mineral parajenezi içermektedir. Monzogranit bileşimli Acıgöl plütonu ana bileşen olarak; kuvars, K.feldispat (ortoklaz, mikroklin), plajiyoklaz, biyotit ve nadir olarak amfibol içerir (Çizelge 1). Tali bileşen olarak; titanit, apatit ve opak, ikincil ürün olarak klorit ve serisit mineralleri gözlenir. Kuvars monzonit ve kuvars monzodiyorit bileşimine sahip kayaçlar ise ana bileşen olarak; plajiyoklaz, K.feldispat (ortoklaz, mikroklin), kuvars, amfibol, tali bileşen olarak; biyotit, piroksen, titanit, apatit, opak minerallerinden oluşmaktadır. İkincil ürün olarak klorit, serisit, karbonatlaşma ve kaolenleşmeler gözlenmektedir.

Monzogranit ve kuvars monzonit/ monzodiyorit bileşimli plütonik kayaçlarda kuvarslar öz şekilsiz - gelişigüzel biçimlerde ve diğer minerallerin arasını doldurmuş ksenomorf şekillerde gözlenmektedir. Plajiyoklazlar öz şekilli - yarı öz şekilli kristaller halinde, polisentetik ve zonlu ikizlenme sunar. Plajiyoklazlarda yaygın olarak gözlenen alterasyon serisitleşmedir. Bazı plajiyoklazlarda magma mixing süreçlerinin kanıtı olan erime-çözünme dokusu ve plajiyoklazlar içerisinde kapanımlar şeklinde gözlenen lataşekilli plajiyoklazların varlığ́ önemli dokusal farklılıklardır. Ortoklazlar yarı öz şekilli / öz 
şekilsiz ve diğer mineraller arasını doldurur şekilde veya poikilitik dokuda gelişmiştir. Amfibol mineralleri öz şekilli veya altıgen biçimli bazı minerallerinde ise yarı öz şekilli prizmatik biçimli olarak izlenir (Şekil 6 b, d). Yüksek girişim renkleri sunan amfiboller yeşilden koyu yeşile değişen tonlarda pleokroyizma sunar. Yarı öz şekilli - öz şekilli levhamsı kristaller halinde bulunan biyotitler ise, tek yönde dilinimi, pulsu sönme özelliği ve kahverengi tonlarında kuvvetli pleokroyizması ile karakteristiktir. Amfibol ve biyotitlerin kenar ve dilinim izleri boyunca kloritleştiği gözlenir. Bazı amfibol ve biyotitlerde, eşyaşlı mafik ve felsik magmaların kimyasal karışımı (magma mixing) ile etkileşimi sonucu meydana gelen hibrid magmanın ürünleri olan kuvars, plajiyoklaz ve opak mineral kapanımları şeklinde afinitik dokular da tanımlanmıştır (Şekil 6b). Titanit, özşekilli ve yüksek optik engebesi ile karakteristiktir (Şekil 6b). Titanit gibi yüksek optik engebe sahip ksenotim, yüksek girişim renkleri ile titanitten ayırt edilmektedir.

Acıgöl ve Akçataş plütonlarında değişik boyutlarda gözlenen kuvars monzodiyorit ve monzodiyorit bileşimli (Şekil 5) mafik mikrogranüler anklavları benzer ana kayaç mineral parajenezine sahip olup, kuvars bolluğu oldukça düşüktür. İnce-taneli hipidiyomorfik dokuya sahip anklav örneklerinin ana kayasında olduğu gibi ortoklazlarda poikilitik dokular hakimdir (Şekil 6c). Ortoklazlar içerisinde amfibol, biyotit, plajiyoklaz ve iğnemsi apatit kristalleri kapanımlar şeklinde gözlenir. Aplit damarları ince-taneli hipidiyomorfik dokuda ve ana bileşen olarak kuvars, K-feldispat, plajiyoklaz ve biyotit minerallerinden oluşmaktadır (Çizelge 1). Kayaç felsik bileşenlerce zengin olup mafik mineral olarak az oranda biyotit içerir.
Bayramhacı ve İdişdă̆ plütonu ince-orta taneli hipidiyomorfik doku özelliği sunarken (Şekil 6f, 1), eş kökenli subvolkanik kayaçlar ise hipokristalin porfirik dokuludur (Şekil $6 \mathrm{~g}, \mathrm{~h}, \mathrm{j}$, k). Monzogranit ve kuvars monzonit bileşimli kayaçlar ana bileşen olarak kuvars, K.feldispat (ortoklaz), plajiyoklaz, amfibol, biyotit ve/veya piroksenlerden oluşmaktadır. Tali bileşen olarak titanit, ksenotim, apatit, opak ve ikincil ürün olarak epidot, serisit, klorit, karbonat ve kaolinit mineralleri diğer gözlenen minerallerdir.

Kuvarslar genellikle öz şekilsiz ve diğer minerallerin arasını doldurmuş ksenomorf formdadır (Şekil 61). Polisentetik ve zonlu ikizlenmeler sunan plajiyoklaz mineralleri öz şekilli - yarı öz şekilli kristaller şeklindedir. Plajiyoklaz ve ortoklazların serisitleștiği, serisitleşmenin ileri aşaması olan ortoklazların kaolenleştiği ve plajiyoklazlarda gözlenen karbonatlaşmalar tanımlanan alterasyon türleridir. Amfibol genellikle yarı öz şekilli kristaller halindedir ve plajiyoklaz kapanımları içerir (Şekil 6f, 1). Mavimsi yeşil rengi ve değişen yeşilkahve renklerinde pleokroziması ile karakteristik olan amfiboller muhtemel olarak arfvedsonit bileşimindedir. Yüksek optik engebesi, yeşil renkte zayıf pleokroizması ve yüksek girişim renkleri ile karakteristik olan piroksenler ise muhtemel olarak egirin bileşimindedir (Şekil 61). Bazı örneklerde izlenebilen biyotitler pulsu sönme özelliği ve yeşil renk tonlarında kuvvetli pleokroizması ile karakteristiktir. Epidot ise açık yeşil rengi ve yüksek girişim renkleri sunmaktadır. Kuvarsça fakir monzonitik bileşimli iki örnekte ise feldispat bolluğu yüksektir (Şekil 6f). 

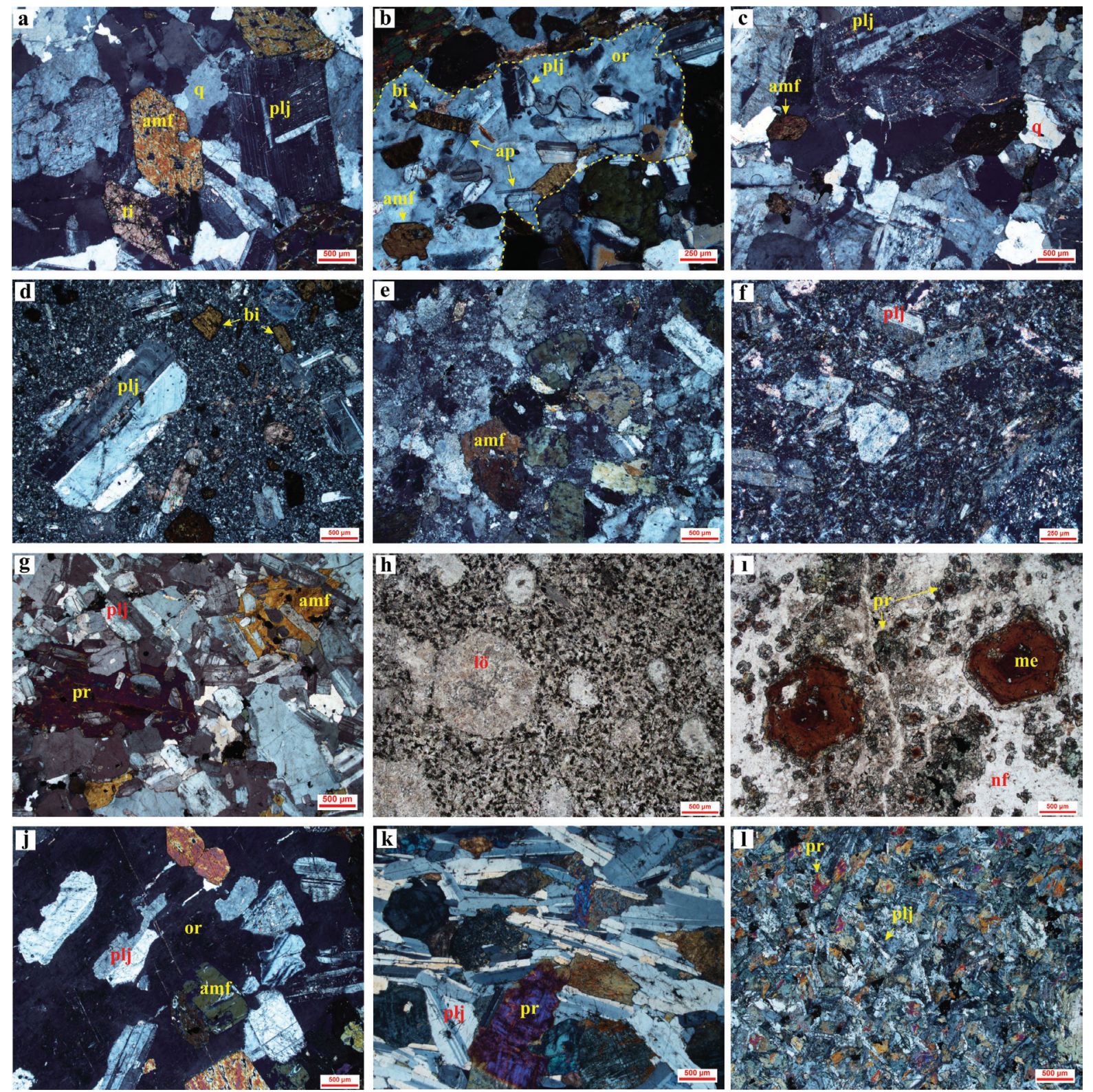

Şekil 6. (a) Acıgöl plütonu (AG-2), (b) Akçataş plütonu (AK-1) (c) Akçataş MME (AK-12), (d) Göynük plütonu (GR-3), (e) Karadağ subvolkanik (KD-3), (f) Bayramhacı plütonu (BH-6), (g, h) Bayramhacı subvolkanik (BH-12 ve BH-14), (1) İdişdağı plütonu (GB-19), (j, k) İdişdağı subvolkanik (GB-3 ve GB-8), (1) İdişdağı aplitine (GB-13) ait örneklerin mineral topluluğu ve dokusal özelliklerinin mikroskop görüntüleri (amf; amfibol, ap; apatit, bi; biyotit, lö; lösit, me; melanit, nf: nefelin; nö; nozeyan or; ortoklaz, plj; plajiyoklaz, pr; piroksen, q; kuvars, ti; titanit) (a, b, c d, e, f, g, 1 ve h, j, k, 1 mikrofotograflar çift ve tek nikol).

Figure 6. Photomicrographs of the mineral assemblages and textural properties in the (a) Actgöl pluton (AG-2), (b) Akçataş pluton (AK-1), (c) Akçataş mafic enklave (AK-12), (d) Göynük pluton (GR-3), (e) Karadăg subvolcanite (KD-3), (f) Bayramhacl pluton (BH-6), (g, h) Bayramhacı subvolcanite (BH-12 and BH-14), (l) İdişdăgl pluton (GB-19), (j, k) İdişdağ subvolcanite (GB-3 and GB-8), (l) İdişdă̆l aplite (GB-13) (amf; amphibole, ap; apatite, bi; biotite, lö; leucite, me; melanite, nf: nepheline; nö; nösean, or; orthoclase, plj; plagioclase, pr; pyroxene, q; quartz, ti; titanite) ( $a, b, c d, e, f, g, l$ and $h, j, k, l$ photomicrographs are in (+) and (-) nicols). 
Kuvars içermeyen subvolkanik kayaçları feldispatoid mineralleri (nefelin/lösit) ve/veya feldispat mineralleri açısından zengindir (Şekil $6 \mathrm{~g}, \mathrm{~h}, \mathrm{j}, \mathrm{k})$. Ayrıca alkalin kayaçlarda yaygın olarak gözlenen nozeyan, melanit ve piroksen gibi mineraller içermektedir. Bu kayaçlarda genellikle öz şekilli ve uzun latalar şeklinde gözlenen ortoklazlar oldukça alteredir (Şekil 6j). Lösitler ise dairemsi / sekiz köşeli şekli, düşük optik engebesi ve izotrop özelliği ile karakteristiktir (Şekil 6j, k). Nefelinler; renksiz, optik engebesi düşük ve öz şekilsizdir. Bu mineraller genellikle diğer minerallerin arasındaki boşlukları doldurur şekilde ksenomorf formda gelişmiştir (Şekil 6h). Nozeyan kristalleri öz şekilli - yarı öz şekilli, renksiz ve izotrop özelliktedir (Şekil 6h). Melanit ise yüksek optik engebesi, kahverengi ve izotrop özelliği tanımlanabilmektedir (Şekil 6h). Aplitik dayka ait bir örnek ise nefelin, melanit ve piroksen mineralleri içermektedir (Şekil 61). Melanit genellikle öz şekilli, altı köşeli ve zonlu yap1 sunmaktadır. Melanitlerin kenarları genellikle piroksenler tarafindan kuşatıldığı gözlenir. Özşekilsiz ve hâkî yeşil renkte gözlenen piroksenler muhtemel olarak egirin bileşimindedir.

\section{JEOKİMYASAL ÖZELLİKLER}

Nevşehir'in kuzeyi ve güneyinde farklı doku ve bileşimdeki plütonik ve subvolkanik kayaçların ana oksit ve iz element sonuçları ve ana oksit element sonuçlarından hesaplanmış CIPW normları Çizelge 2'de sunulmuştur. $\mathrm{Bu}$ analiz sonuçları kullanılarak magmatik kayaçların sinıflandırılması ve magma tipini belirlemek amacıyla farklı diyagramlarda değerlendirilmiştir.

$\mathrm{SiO}_{2}$ içerikleri monzogranit bileşimli kayaçlardan (\% 62.56 - 75.74) kuvars monzonit / monzodiyorit (\% 56.58 - 66.39), monzonit (\% $58.07-59.78)$ ve fonolitik tefrit / tefritik fonolit kayaçlara (\% 45.45 - 51.75) doğru azalırken $\mathrm{NaO}+\mathrm{K}_{2} \mathrm{O}$ içeriklerinin arttığ gözlenmektedir (Şekil 7). Toplam alkali-silis $\left[\left(\% \mathrm{NaO}+\mathrm{K}_{2} \mathrm{O}\right)-\right.$ $\% \mathrm{SiO}_{2}$ ] diyagramında (Irvine ve Baragar, 1971) monzogranit - kuvars monzonit / monzogranit bileşimli kayaçlar (Akçataş, Acıgöl, Yeşilöz, Göynük, İdişdağı ve Bayramhacı plütonu ve Karadağ subvolkaniti) subalkali özelliği sunarken, monzonit - fonolitik tefrit/tefritik fonolit arasında bileşim sergileyen Bayramhacı ve İdişdağ plütonik / subvolkanik kayaçları alkali özelliğe sahiptir. $\mathrm{K}_{2} \mathrm{O}-\mathrm{SiO}_{2}$ diyagramında (Rickwood, 1989), Acıgöl plütonu ve Karadağ subvolkaniti yüksek-K kalk-alkalen karakter sunarken diğer magmatik kayaçlar yüksek-kalk-alkalen ile şoşonitik seri arasında bileşim sergilemektedir (Şekil 8a). Nevşehir Bölgesindeki magmatik kayaç örneklerinin çoğu, Maniar ve Picoli (1989)'un mafik mineral kimyasına göre yaptığ 1 sınıflamada, I-tipi granitleri için karakteristik olan metaluminus bölgesine $(\mathrm{mol} \mathrm{A} / \mathrm{CNK}<1)$ karşılık gelmektedir (Şekil 8b, Çizelge 2). Acıgöl ve Yeşilöz plütonuna ait örneklerin tamamı ve İdişdağ1 plütonuna ait granitik bileşimli iki adet örnek I-S ayırım çizgisi ile metaluminus arasında kalan alanda yer almaktadır. 

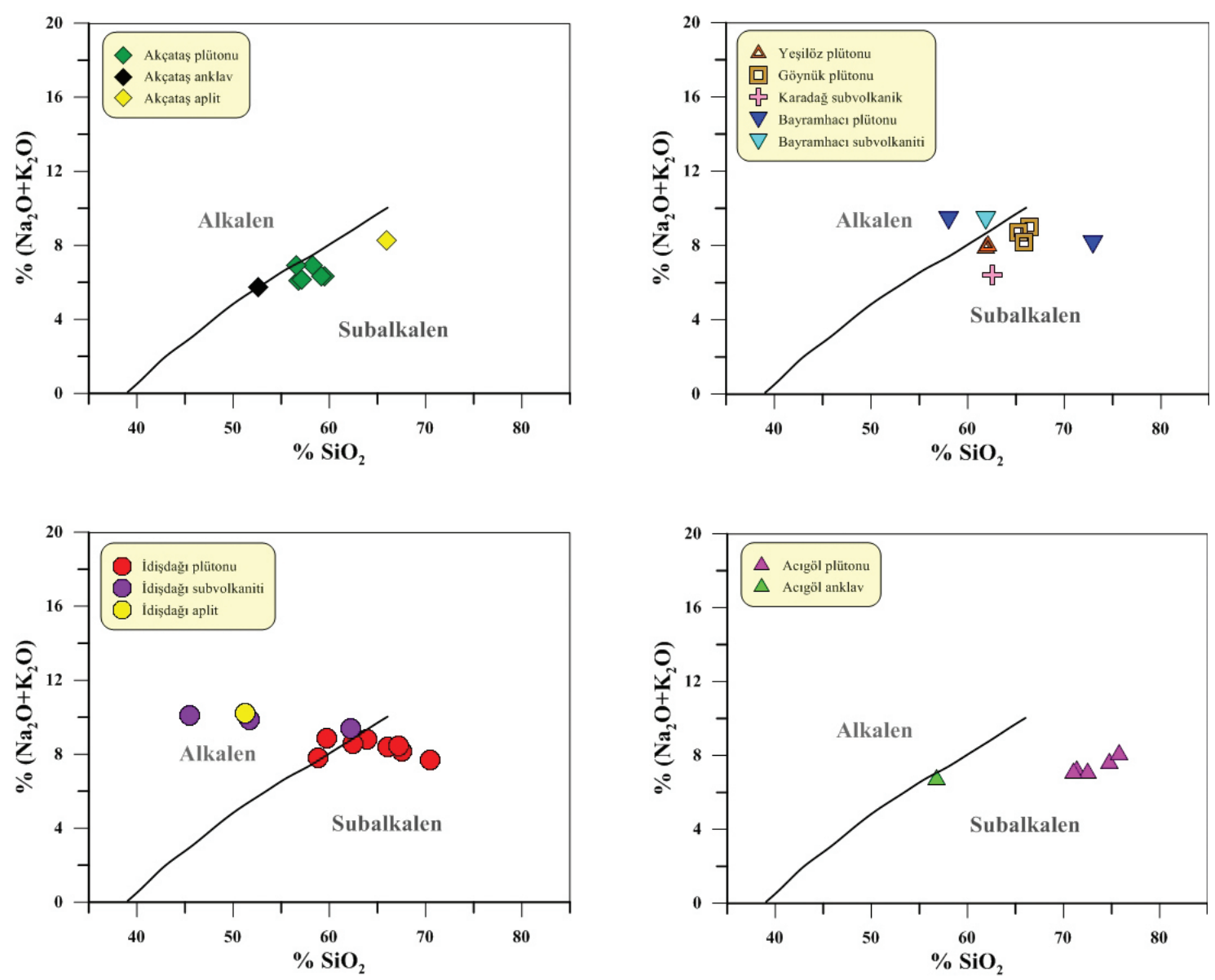

Şekil 7. Nevşehir Bölgesi plütonik, subvolkanik, MME ve aplitik dayk kayaç örneklerinin toplam alkali-silika $\left[\left(\% \mathrm{NaO}+\mathrm{K}_{2} \mathrm{O}\right)-\% \mathrm{SiO}_{2}\right]$ diyagramında sinıflamas1 (Irvine ve Baragar, 1971).

Figure 7. Classification of plutonic, subvolcanite, MMM and aplitic dyke rock samples from the Nevşehir Region in total alkalis-silica $\left[\left(\% \mathrm{NaO}+\mathrm{K}_{2} \mathrm{O}\right)-\% \mathrm{SiO}_{2}\right]$ diagram (Irvine and Baragar, 1971).

Nevşehir Bölgesine ait bütün magmatik kayaç örneklerinin kondrite göre normalize edilmiş nadir toprak element (NTE) diyagramları Şekil 9'da verilmiştir. Bütün örneklerde NTE bollukları kondrite göre zenginleşme gösterirken monzogranit bileşimdeki Acıgöl plütonunun zenginleşme derecesi diğer plütonlara göre daha düşüktür (Şekil 9d). Subalkalen karakter sunan monzogranit bileşimli plütonik kayaçlardan alkalen karakterli monzonit ve foid içeren plütonik ve subvolkanik kayaçlara doğru NTE bollukları kondrite göre zenginleşme eğilimlidir (Şekil 9a, b, c). Nevşehir Bölgesindeki bütün magmatik kayaçların hafif nadir toprak elementlerinin zenginleşme derecesi (HNTE) ağır nadir toprak elementlerine (ANTE) göre daha fazladır. Ağır nadir toprak elementlerindeki $[(\mathrm{La} / \mathrm{Yb})$ $\left.{ }_{n}=(\mathrm{La} / 0.237) /(\mathrm{Yb} / 0.17)\right]$ normalize değerler (Sun ve McDonough, 1989), Akçataş plütonu 12.06 - 20.20, Karadağ subvolkaniti 18.36, Yeşilöz plütonu 22.95 - 26.35, Göynük plütonu 25.46 32.52 Bayramhacı plütonu / subvolkanitinde14.45 - 27.18 arasında değerler sunarken, bu değerler Acıgöl plütonuna göre $(4.58$ - 12.11) yüksektir 
(Çizelge 2). Subalkalen ve alkalen karakterli İdişdağı plütonu / subvolkanitinde ise ağır nadir toprak elementlerindeki (HNTE) zenginleşme oranı (23.29 - 82.17) diğer plütonik /subvolkanik kayaçlara göre yükselme eğilimlidir. Acıgöl plütonu belirgin negatif-Eu $\left(\mathrm{Eu} / \mathrm{Eu}^{*}=0.32-\right.$ 0.73) anomalisi göstermekte ve diğer plütonik / subvolkanik ve alkalen kayaçlarda genel olarak (Bayramhacı plütonunda bir örnek hariç) belirgin olmayan negatif-Eu anomalisi $(0.58-0.82$ ve $0.57-0.70)$ gözlenmektedir.

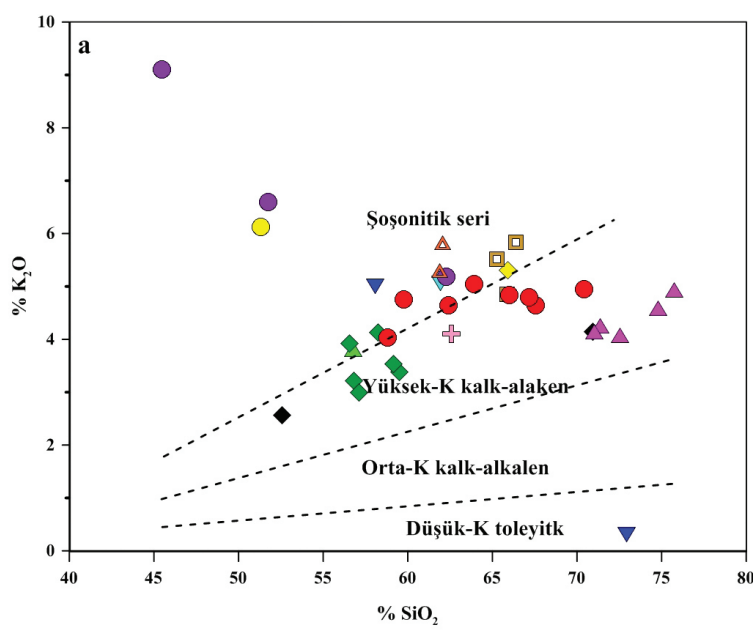

$\mathrm{Nb}$ ve $\mathrm{Zr}$ elementleri tüketilme eğilimindedir. Nevşehir bölgesindeki magmatik kayaçların iz elementlerdeki değişimleri magmanın yitim zonu ve/veya çarpışma ile ilişkili tektonik yerleşimden türediğine işaret etmektedir (Pearce vd., 1984). Acıgöl plütonundaki $\mathrm{Ba}$, Ta ve $\mathrm{Nb}$ tüketimi diğer plütonik ve subvolkanik kayaçlara göre daha belirgindir.

Nevşehir Bölgesindeki plütonik ve subvolkanik kayaçlara ait örneklerin çoğu Pearce

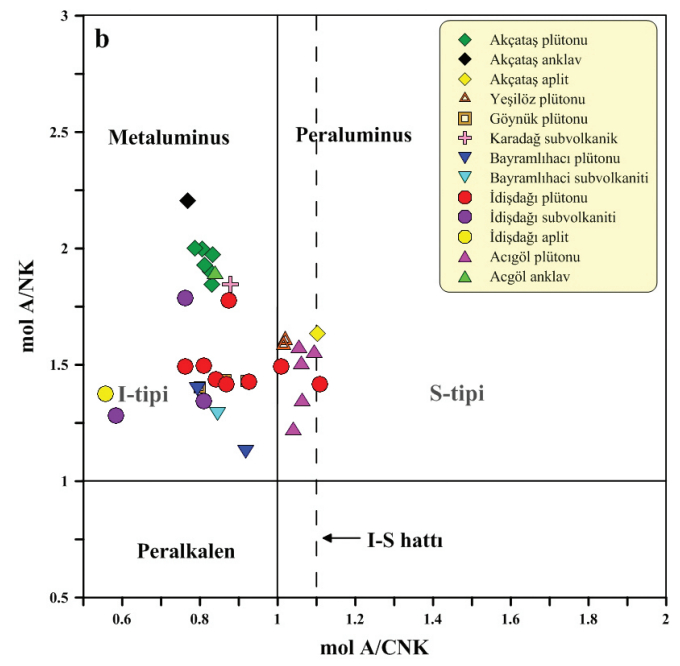

Şekil 8. Nevşehir Bölgesi plütonik, subvolkanik, $\mathrm{MME}$ ve aplitik dayk kayaçların (a) $\mathrm{K}_{2} \mathrm{O}$ karşı $\mathrm{SiO}_{2}$ diyagramında (Rickwood, 1989), (b) A/NK $\left[\left(\mathrm{Al}_{2} \mathrm{O}_{3} /\left(\mathrm{Na}_{2} \mathrm{O}+\mathrm{K}_{2} \mathrm{O}\right)\right]-\mathrm{A} / \mathrm{CNK}\left[\left(\mathrm{Al}_{2} \mathrm{O}_{3} /\left(\mathrm{CaO}+\mathrm{Na}_{2} \mathrm{O}+\mathrm{K}_{2} \mathrm{O}\right)\right]\right.\right.$ oranına göre (Maniar ve Piccoli, 1989) sinıflandırılması.

Figure 8. Classification of plutonic, subvolcanite, $M M M$ and aplitic dyke rocks from the Nevşehir Region in (a) $\mathrm{K}_{2} \mathrm{O}$ vs. $\mathrm{SiO}_{2}$ diagram (Rickwood, 1989), (b) mol A/NK $\left[\left(\mathrm{Al}_{2} \mathrm{O}_{3} /\left(\mathrm{Na}_{2} \mathrm{O}+\mathrm{K}_{2} \mathrm{O}\right)\right]-\mathrm{A} / \mathrm{CNK}\left[\left(\mathrm{Al}_{2} \mathrm{O}_{3} /\left(\mathrm{CaO}+\mathrm{Na}_{2} \mathrm{O}+\mathrm{K}_{2} \mathrm{O}\right)\right]\right.\right.$ ratio (Maniar and Piccoli, 1989).

Çalışma alanına ait plütonik ve subvolkanik kayaçların okyanus sırtı granitlere (ORG) göre normalize edilmiş çoklu element diyagramlarında (Şekil 10), bütün magmatik kayaçlar büyük iyon çaplı litofil elementler açısından (LILE: K, Rb, Ba gibi) kalıcılığ 1 yüksek elementlere (HFSE: Ta, Nb, $\mathrm{Hf}, \mathrm{Zr}$, Y gibi) göre zenginleşme göstermektedir. Bölgedeki magmatik kayaçların tamamında Ta, vd. (1984)'ün granitler için ayırtman Rb - [Y+Nb] diyagramında çarpışma sonrası (post-COLG) için karakteristik olan volkanik yay granitleri (VAG) alanına düşmektedir (Şekil 11a). Acıgöl plütonu ve İdişdağ1 subvolkanitine ait bir adet örnek synCOLG alanına düşen değerler vermiştir. İdişdağ 1 plütonunu kesen aplit dayk örneği, bir adet subvolkanit örneği ve Bayramhacı plütonuna ait 
bir örnek WPG sınırında yer almaktadır. Bölgedeki magmatik kayaçlar $\mathrm{La} / \mathrm{Yb}$ ve $\mathrm{Th} / \mathrm{Yb}$ oranları ile kıtasal yay granitoyidleri ile uyumlu değerler
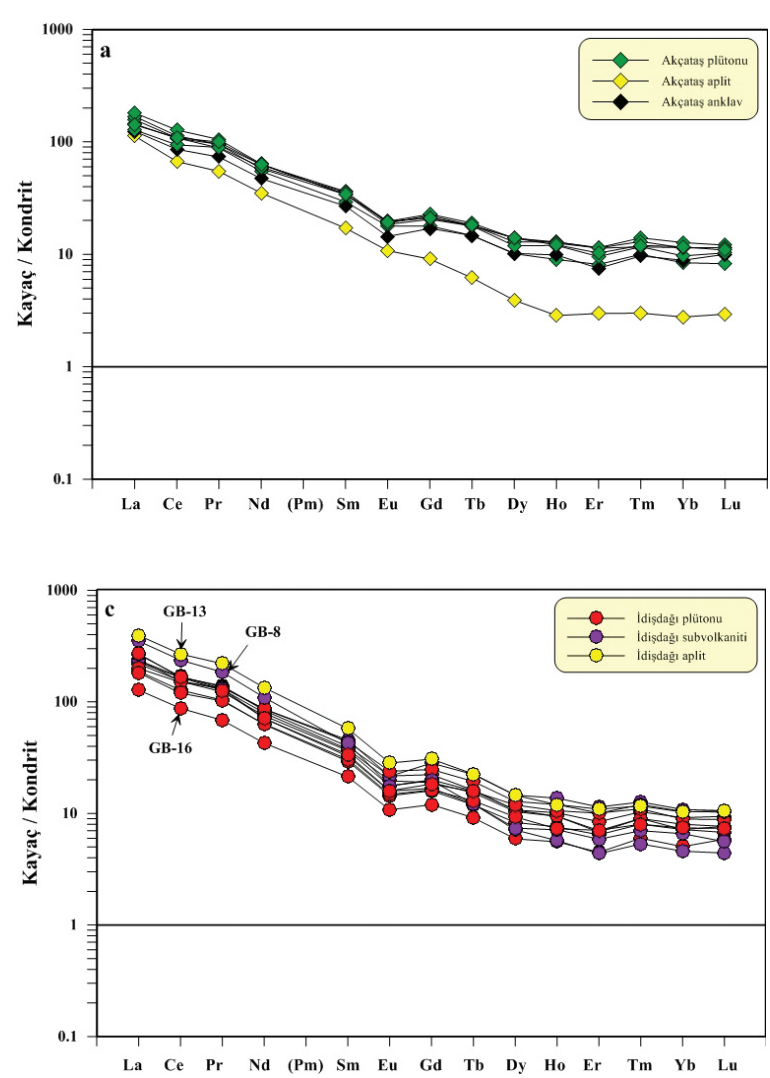

sunmaktadır (Şekil 11b). La/Yb ve Th/Yb oranları Acıgöl Plütonundan İdişdağ subvolkanitine doğru artış eğiliminde değerlere sahiptir.
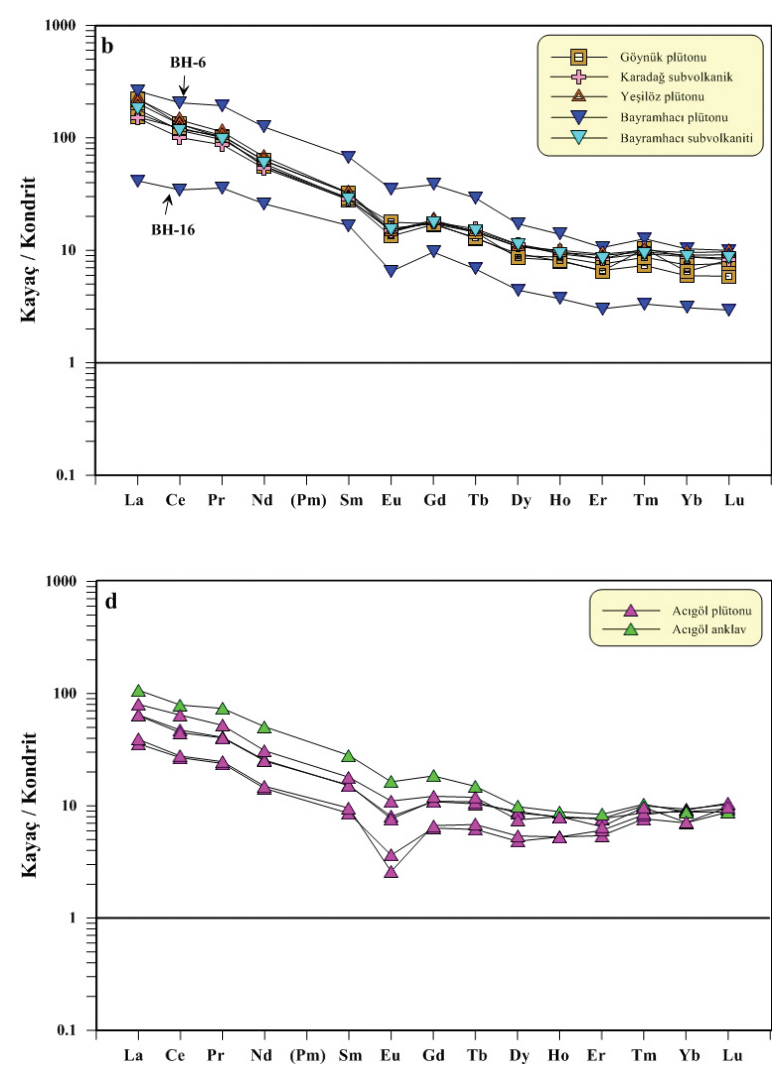

Şekil 9. Nevşehir Bölgesi plütonik, subvolkanik, MME ve aplitik dayk örneklerinin kondritlere normalize edilmiş NTE desenleri (kondritlere normalize değerler Nakamura 1974'den alınmıştır).

Figure 9. Chondrite-normalized REE patterns for the plutonic, subvolcanite, MMM and aplitic dyke samples from the Nevşehir Region (normalizing values are taken from Nakamura, 1974). 

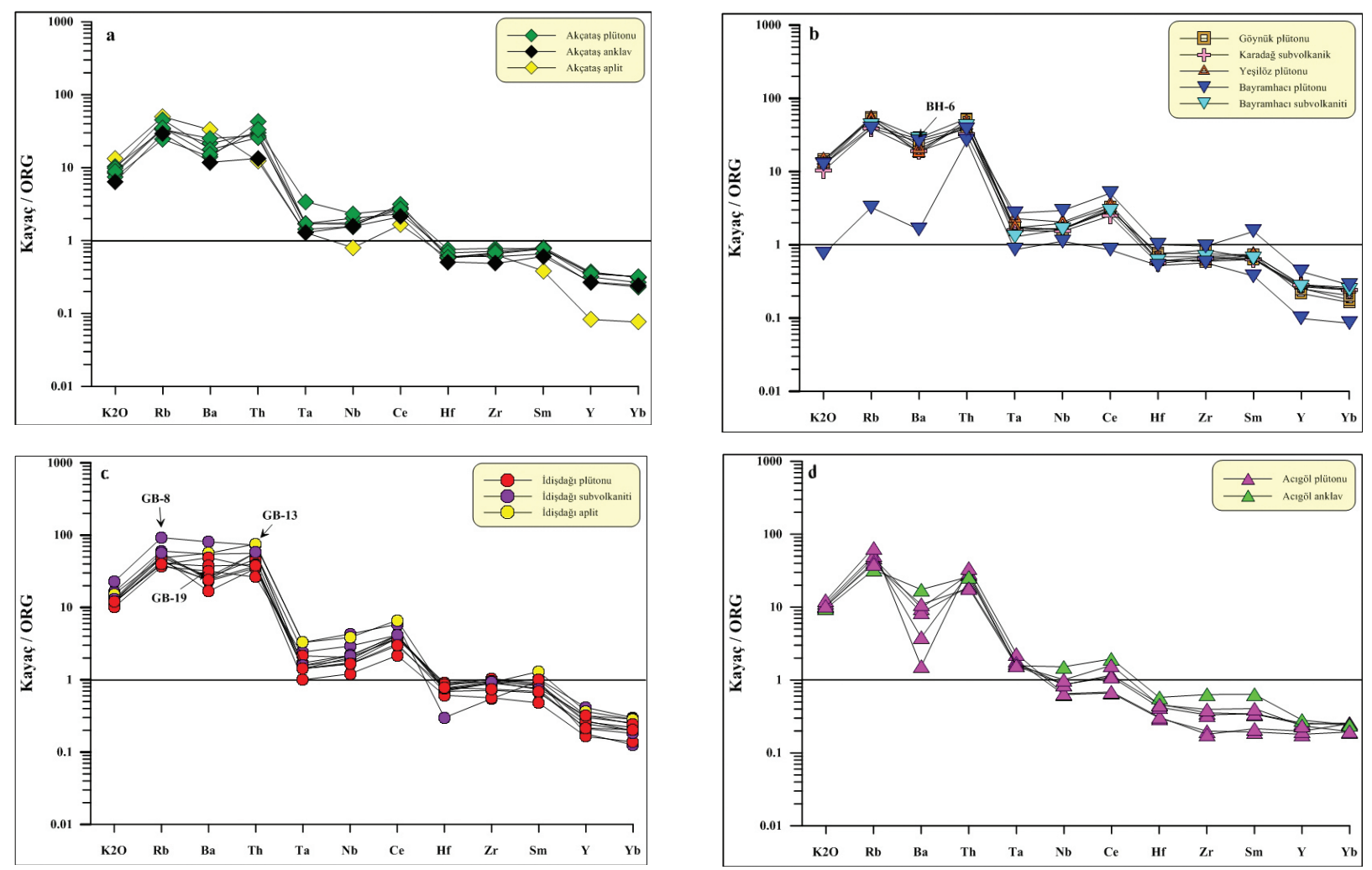

Şekil 10. Nevşehir Bölgesi plütonik, subvolkanik, MME ve damar kayaçların kayaçların ORG normalize edilmiş çoklu element diyagramları (ORG normalize değerler Pearce vd., 1984'den alınmıştır).

Figure 10. ORG-normalized multi element diagrams for the plutonic, subvolcanite, MMM and aplitic dyke samples from the Nevşehir Region (normalizing values are taken from Pearce et al., 1984).
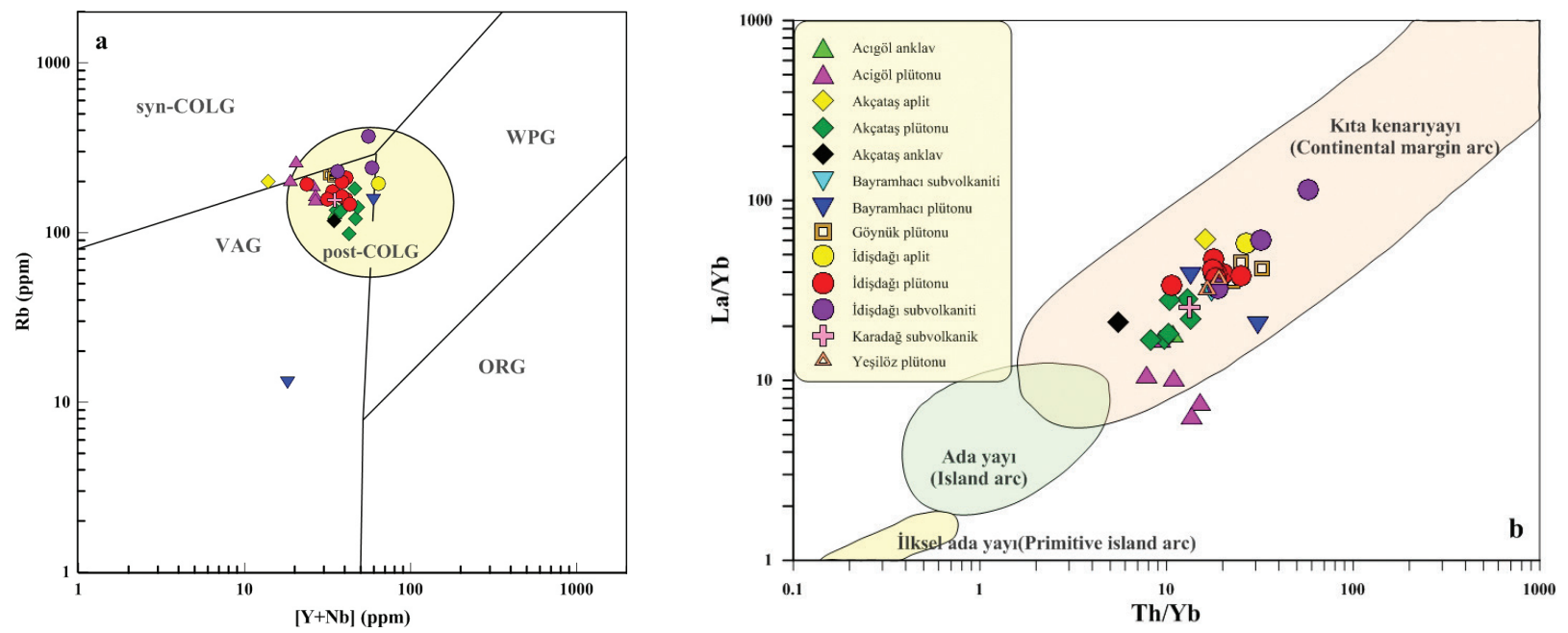

Şekil 11. Nevşehir Bölgesi plütonik, subvolkanik, MME ve damar kayaçların kayaçların (a) Rb karş1 [Y+Nb] (Pearce vd., 1984) ve (b) La/Yb karşı Th/Yb (Condie, 1989) tektonik diyagramlarında gösterilmesi.

Figure 11. (a) Rb vs. [Y+Nb] (Pearce et al., 1984) and (b) La/Yb vs. Th/Yb (Condie, 1989) tectonic diagrams for the the plutonic, subvolcanite, MMM and aplitic dyke samples from the Nevşehir Region. 


\section{TARTIŞMA VE SONUÇLAR}

Nevşehir (Kapadokya) bölgesinde farklı doku, mineralojik bileşim ve jeokimyasal özelliklere sahip üç tip plütonik ve/veya subvolkanik kayaç yüzeylemektedir. Bu kayaçlar monzogranit, kuvars monzonit / kuvars monzodiyorit ve monzonit / foid bileşimindedir ve petrojenetik özelliklerini şu şekilde özetleyebiliriz:

(I) Monzogranit bileşimli kayaçlar, ana bileşen olarak kuvars + plajiyoklaz + iri-K.feldispat + biyotit minerallerinin yanı sıra (Çizelge 1) bazı örneklerde amfibol minerali de içermektedir. Monzogranit bileşimli kayaçların tamamı subalkalen (Şekil 7), yüksek-K ve kalk-alkalen (Şekil 8a, b) karakterli ve I-tipi magma (Şekil 8b) özelliği sunmaktadır. Ayrıca bu kayaçlar az bollukta MME ve iri K-feldispat megakristalleri (Şekil 4a) gözlenmektedir. Akıman vd. (1993), Aydın vd. (1998), Tatar ve Boztuğ (2005) ve Kadıoğlu vd. (2006) tarafından MME ve iri-K.feldispat içeren löko-granitler Orta Anadolu Plütonları içerisinde erken granitoid evresini temsil eden kitasal kabuk katkısı yüksek magmatik kaynaktan türemiş granitoyidler içerisinde sınıflandırmışlardır. Kadıoğlu vd. (2006) tarafindan löko-granit bileşimli (granite-suit) kayaçların Ar/Ar yaşı

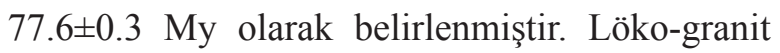
bileşimli Acıgöl plütonunun yaşı Aydar vd. (2012) tarafindan ise $\mathrm{Ar} / \mathrm{Ar}$ ve $\mathrm{Pb} / \mathrm{U}$ yöntemiyle benzer şekilde $78.44 \pm 0.29$ My ve $77.8 \pm 4.4$ My olarak tespit edilmiştir. Acıgöl Plütonunun $\mathrm{A} / \mathrm{CNK}$ oranı 1.04 ila 1.09 arasında (Çizelge 2) ve $\mathrm{A} / \mathrm{CNK}<1.1$ olması ile zayıf peralüminalı özellik sunmaktadır (Chappel ve White, 1974). Plütonik kayaçlarda hesaplanmış CIPW-normatif korundum değeri ise 0.49 ve 0.91 arasindadır (AG-1 nolu örnek hariç). Chappel ve White (2001)'e göre S-tipi granitler için CIPW normatif korundum değeri $>1.0$ olarak tanımlanmıştır. Plütonik kayaç, Rb$(\mathrm{Y}+\mathrm{Nb})$ tektonik ayırtman diyagramında (Pearce vd. 1984) post-COLG alanında (bir örnek hariç) yer almaktadır (Şekil 11). Gerek mineralojik ve jeokimyasal özellikleri gerekse jeokronolojik verileri dikkate alındığında löko-granit bileşimli Acıgöl plütonunun Orta Anadolu Granitoyidleri içerisinde erken evreyi temsil eden kitasal kabuk katkısı yüksek bir magmatik kaynaktan türediği anlaşılmaktadır. Plütonun HNT elementlerinin zenginleşme oranı da $\left.(\mathrm{La} / \mathrm{Yb})_{\mathrm{n}}=4.58-12.11\right)$ diğer plütonik / subvolkanik kayaçlara göre düşük değerlerdedir (Çizelge 2). Ayrıca, Acıgöl Plütonunun ANTE'lerin tüketilmesi ile birlikte HNTE'lerin zenginleşmesi ve belirgin negatif$\mathrm{Eu}\left(\mathrm{Eu} / \mathrm{Eu}^{*} 0.32\right.$ - 0.73) anomalisi sunmas amfibol ve plajiyoklazın fraksiyonlaşmasına işaret etmektedir.

Oldukça geniş bir bileşim sergileyen İdişdağı plütonuna ait silisçe aşırı doygun iki örneğinde (GB-16 ve GB-28) CIPW-normatif korundum değeri 0.33 ve 1.86 'dir. $\mathrm{Bu}$ değerler plütonun kıta kabuğu karışımına uğramış olabileceğini göstermektedir. Benzer özellik sergileyen Yeşilöz plütonu da kıta kabuğu karışımına işaret etmesine karşın, plütona ait kuvars monzonitik bileşimli kayaçlar şoşonitik karakter sunmaktadır.

(II) Nevşehir (Kapadokya) bölgesinde kuvars monzonit ve kuvars monzodiyorit bileşimli kayaçlar, ana bileşen olarak plajiyoklaz + iri K-feldispat megakristalleri + kuvars + amfibol + biyotit mineralleri içermekte bazı örneklerde piroksen gözlenmektedir (Çizelge 1). Bu plütonik kayaçlar subalkalen (Şekil 7), yüksek-K kalkalkalen ile şoşonitik arasında değişen (Şekil 8a) ve I-tipi magma (Şekil 8b) karakteri sergilemektedir. Kayaçların makro ve mineralojik özellikleri ve tüm kayaç jeokimyası yaygın olarak mafik ve felsik magmanın karışımı ile hibrid bir kökenden türediğine işaret etmektedir (Barbarin, 1999, Hibbard, 1991). Magma karışımına işaret eden bulguları; (a) magmatik kayaçların mafik mikrogronular anklav ve/veya iri-K. feldispat kristalleri içermesi (Şekil 4b, c), (b) bazı plajiyoklazların homojen magma karışımı (magma mixing) yansıtan erime-çözünme dokusu göstermesi ve iri plajiyoklazlar içinde lata şekilli plajiyoklazların varlığı, (c) poikilitik doku sunan 
ortoklazların amfibol, biyotit, plajiyoklaz ve apatit kristalleri içermesi (Şekil 6c), (d) bazı amfibol ve biyotitlerin kuvars, plajiyoklaz ve opak mineral kapanımları ile afinitik dokular sunması (Şekil 6b) ve (e) MME içerisinde iğnemsi apatit kristallerinin gelişmesi (Şekil 6c) şeklinde özetleyebiliriz. Orta Anadolu plütonik kayaçlar içerisinde bu özelliklere sahip granitoyidler, Akıman vd. (1993), Aydın vd. (1998) ve Kadığlu vd. (2006) tarafindan alt kita kabuğu ve manto kaynaklı malzemeden türemiş I-tipi plütonlar olarak sınıflandırılmıştır. Kuvars monzonit bileşimli ve şoşonitik karakterde magmatik kayaçların Ar-Ar yaşı ise Kadıoğlu vd. (2006) tarafından

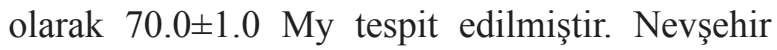
bölgesinde Akçataş (aplit daykı hariç), Göynük, Yeşilöz plütonu ve Karadağ subvolkanitine ait kayaçların tamamı ve Bayramhacı ile İdişdağı plütonuna ait bazı örnekler I-tipi plüton özelliği sunmaktadır. Plütonik kayaçlarda (anklav örnekleri hariç) $(\mathrm{La} / \mathrm{Yb})_{\mathrm{n}}$ oranının geniş aralıkta değişmesi (12.06 - 33.78) felsik ve mafik magmaların değişen fiziksel koşullar altında hibritleşmenin göstergesi şeklinde yorumlanabilir. Yüksek $(\mathrm{La} / \mathrm{Yb})_{\mathrm{n}}$ oranı ise magma kaynağı olarak kalıntı granatlı-honblend içeren alt kıta kabuğunu yansitmaktadır (Reichardt ve Weinberg, 2012). Bu plütonik kayaçların ANTE'lere göre zenginleşmiş HNTE desen sunması ve belirgin olmayan negatif-Eu $\left(\mathrm{Eu} / \mathrm{Eu}^{*} 0.58\right.$ - 0.75$)$ göstermesi fraksiyonel kristallenmeye işaret etmektedir. Plütonik kayaçların tamamı Pearce vd. (1984)'in $\mathrm{Rb}-(\mathrm{Y}+\mathrm{Nb})$ tektonik ayırtman diyagramında VAG ve post-COLG alanında yer almaktadır (Şekil 11). Nevşehir bölgesindeki kalk-alkalen ve şoşonitik karakterli magmatik kayaçların tamamı $\mathrm{Ta}, \mathrm{Nb}$, $\mathrm{Hf}, \mathrm{Zr}$, Y ve $\mathrm{Yb}$ elementlerine göre zenginleşmiş $\mathrm{K}, \mathrm{Rb}, \mathrm{Ba}, \mathrm{Th}, \mathrm{Ce}$ ve Sm desenleri (Şekil 10 a, b, c) ile karakteristik VAG özelliği sunmaktadır (Pearce vd., 1984).

(III) Kuvars içeriği oldukça düşük monzonit / foid içeren fonolitik tefrit ve tefritik fonolit bileşimli plütonik / subvolkanik kayaçlar farklı mineral parajenezlerine sahiptir. Kuvars oran1 düşük ve feldispat (albit, ortoklaz) oranı kısmen yüksek olan monzonit bileşimli plütonik kayaçlar kuvars monzonit / kuvars monzodiyorit bileşimli kayaçlara nazaran farklılık sunmaktadır. $\mathrm{Bu}$ kayaçların CIPW-normatif kuvars değerleri 0.51 - 3.99, albit değerleri 35.20 - 37.82 ve ortoklaz değerleri 28.60 - 30.14 arasındadır (Çizelge 2). Foid içeren kayaçlar ise ana bileşen olarak iri K-feldispat megakristalleri ve/veya lösit kristalleri + nefelin + piroksen içermekte ve bazı örneklerde nozeyan ve melanit gözlenmektedir (Çizelge 1). Tefritik fonolit bileşimli örnekte (GB-3) CIPWnormatif ortoklaz değeri (45.55), nefelin değeri (9.55) ve diyopsit değeri (16.67) oldukça yüksektir (Çizelge 2). Foid monzoditorit / fonolitik tefrit örneğinde ise CIPW-normatif nefelin değeri (5.13 - 17.63) ve diyopsit değeri $(16.31$ - 17.23) yüksek olup ortoklaz değeri düşük (11.52) olan örnekte lösit değeri (37.86) oldukça yüksektir. Monzonit bileşimli ve foid içeren kayaçlar; alkalen (Şekil $7,8 b$ ), şoşonitik (Şekil 8a) ve metaluminus (Şekil 8 b) karakter sunmaktadır. Orta Anadolu plütonları içerisinde alkalen karakterdeki monzonitik/ siyenitik ve foid içeren kayaçlar alt kıtasal parçaları içeren ve büyük miktarda mantodan-türemiş magma katkısı ile gelişmiş A-tipi karakterli plütonlar olarak tanımlanmıştır (Aydın vd., 1998; Boztuğ, 1998; Köksal vd., 2001; Aydın vd., 2001; Kadığlu vd., 2006). Kadığlu vd. (2006) tarafindan nefelin siyenitik kayaçlarda alkalen magmatizmasının Ar-Ar yaş1 69.8土0.3 My olarak tespit edilmiştir. Silikaca-fakir ve silikaca-doygun olmayan Nevşehir Plütonik kayaçları içerisinde İdişdağı ve Bayramhacı plütonik ve subvolkanik kayaçların mineralojik ve jeokimyasal özellikleri Orta Anadolu alkalen magmatizması ile oldukça uyumludur. Alkalen özellik sunan örneklerin çoğunluğu Pearce vd. (1984)'in Rb-(Y+Nb) tektonik ayırtman diyagramında VAG ile WPG sınırında ve post-COLG alanı içerisinde yer almaktadır (Şekil 11a). ORG'a göre normalize edilmiş diyagramlarda granitoyidler I-tipi plütonlar ile benzer yönelimler sunmasına karşın 
düşük negatif-Ba anomalisi ve kısmen yüksek $\mathrm{K}$, Rb ve Th anomalisi (Şekil 10c) ile çarpışma sonrası gelişmiş WPG'nin özelliklerini yansıtmaktadır (Pearce vd., 1984). Silikaca-fakir ve silikacadoymamış alkalen özellik sunan örnekler yüksek $\mathrm{K}, \mathrm{Rb}$ ve Th anomalileri ile kıtasal kabuk karışımını düşündürse de yüksek HNTE içeriği ((La/Yb) $\mathrm{n}=23.29-82.17)$ ile magma kaynağında kalıntı granatın varlığına işaret etmekte (Pertermann vd., 2004) ve kaynak ergiyiğin granat-lerzolitik olduğunu göstermektedir. İdişdağ 1 ve Bayramhac1 plütonik/subvolkanik kayaçlarında silikacafakir magmatizmadan silikaca-doymamış magmatizmaya geçiş nedeni ergime zonundaki su miktarındaki değişimler ile açıklanabilir (Bonin, 1990; Boztuğ, 1997; Aydın vd., 1998). Bonin (1990) tarafindan üst manto veya alt kitanın kısmi ergime zonunda yeterli su olmas1 durumunda kısmi ergimenin tipik olarak kalk-alkalen ve hibrid magmayı ürettiği belirtilmiştir. Aynı araştırmacıya göre yeterli suyun bulunmamas1 durumunda ise kısmi ergimenin LIL (K, Rb ve Th) elementlerince zengin birincil alkalen magmatizmay1 üretmektedir. İdişdağı ve Bayramhacı magmatik kayaçlarına ait silikaca-fakir örnekler, K.feldispat (ortoklaz, albit), piroksen (egirin) ve amfibol (arfvedsonit) mineralleri içerirken silikacadoymamış örnekler ise feldispatoid (nefelin, lösit), nozeyan, melanit ve egirin mineralleri ile karakteristiktir. Düşük su içeriğine sahip silikacafakir magmadan Fe- ve Ti- zengin mafik silikatlar kristallenirken suca tüketilmiş magmadan silikacadoygun olmayan fonolitik tefrit / tefritik fonolit bileşimli kayaçların geliştiği söylenebilir (Bonin, 1990). Alkalen karakterli magmatik kayaçların düşük negatif-Eu $\left(\mathrm{Eu} / \mathrm{Eu}^{*}=0.57-0.70\right)$ (Çizelge 2) ve düşük negatif-Ba anomali (Şekil 10b ve c) sunması ise alkali feldispatın fraksiyonlanması ile açıklanabilir.

Özet olarak Kapadokya bölgesindeki löko-granitler, I-tip ve A-tipi plütonik ve/veya subvolkanik kayaçlar mineralojik ve jeokimyasal özellikleri ve jeokronolojik verileri ile farklılıklar sunmaktadır. Bütünmagmatik kayaçlarzenginleşen LIL (K, Rb, Ba, Th) ve fakirleşen HFS ( Ta, Nb, Hf, $\mathrm{Zr}$, Y gibi) elementleri ve göreceli negatif $\mathrm{Nb}$ ve $\mathrm{Ta}$ anomalileri ile yitim zonu magmatizmasına işaret etse de (Pearce vd, 1984) iz element bollukları köken malzemesinin farklılıklar sunduğunu göstermektedir. Köksal ve Göncüoğlu (2008) tarafindan Orta Anadolu'da S- (löko-granit), I- ve A- tipi plütonik kayaçlarda gerçekleştirilmiş farkl1 radyojenetik izotop sonuçları ile plütonların farklı kaynak özelliklerine sahip olduğu belirlenmiştir. $\mathrm{Bu}$ çalışmalar ile S-tipi granitoyidlerin yüksek ilksel Sr oranları $\left({ }^{87} \mathrm{Sr} /{ }^{86} \mathrm{Sr}_{(\mathrm{i})}=0.7128-0.7152\right)$ ve düşük $\Sigma \mathrm{Nd}_{(\mathrm{i})}(-9.1$ ila -9.7$)$ değerleri ile baskın kıtasal kökenli magmatik kaynaktan türediği belirlenmiştir. Benzer izotop verilerine sahip I- $\left({ }^{87} \mathrm{Sr} /{ }^{86} \mathrm{Sr}_{(\mathrm{i})}=0.7078-0.7109, \Sigma \mathrm{Nd}_{(\mathrm{i})}=-5.4\right.$ ila -7.9) ve A-tipi ${ }^{87} \mathrm{Sr} /{ }^{86} \mathrm{Sr}_{(\mathrm{i})}=0.7082, \Sigma \mathrm{Nd}_{(\mathrm{i})}=$ -7.1) plütonik kayaçların ise hibrit ve heterojen bir kaynaktan türediğini ancak A-tipi magmatik kayaçların alt kıtasal kabuk katkısı ile manto bileşeninin daha baskın olduğu ileri sürülmüştür. Nevşehir Bölgesinde I-tipi özellikteki löko-granit bileşimli Akçataş plütonu I-tipi plütonlara göre az oranda da olsa mikrogronüler mafik anklav içermesi manto katkısına işaret etmektedir. Jeokronolojik ve jeokimyasal verileri birlikte değerlendirildiğinde löko-granit bileşimli Acıgöl plütonunun I- ve A-tipi plütonlara göre yaşl1 ve kıta kabuğu katkısı oranının fazla olduğu anlaşılmaktadır. Alkalen karaktere geçiş özelliği sunan İdişdağ 1 ve Bayramhacı plütonu ve plütonu kesen A-tipindeki subvolkanit ve aplitik kayaçlar daha genç olup iz element bollukları alt kita kabuğu katkısı ile manto bileşenin daha baskın olduğuna işaret etmektedir. Kapadokya Bölgesinde yüzeyleyen plütonik kayaçların löko-granitlerden I- ve A-tipi plütonlara doğru manto kaynağ 1 katkı oranının daha yüksek ve granitoyidlerin Orta Anadolu Plütonları ile oldukça uyumlu olduğu gözlenmektedir.

Orta Anadolu Geç Kretase - Alt Tersiyer zaman aralığında ark arkaya gelişen S-/löko-granitler, 
I- ve A- tipi granitoyidlerin köken malzemesi farklı araştırmacılar tarafından benzer şekillerde tanımlansa da magmanın jeodinamik evrimi farklı modellerle açıklanmıştır. Bazı araştırmacılar tarafindan farklı tipteki magmanın, Neo-Tetis kuzey kolunun kuzeye doğru dalma-batması sonucu İzmir-Ankara-Erzincan Sütur zonunun kapanması ve Anatolid - Pontid çarpışmasına bağlı olarak kısalan ve incelen kabuğun kısmi ergimesi ve çarpışma sonrası gerilme rejimlerine bağlı olarak geliştiği şeklinde yorumlanmaktadır (Akıman vd., 1993; Ekici, 1997; Ekici ve Boztuğ, 1997; Aydın vd., 1998). Bazı araştırmacılar ise, Orta Anadolu Granitoyidlerinin oluşumunu kabuk incelmesini takiben alt kita kabuğuna doğru yükselen sıcak astonosferin neden olduğu litosferin delaminasyonu veya yitim ve yitim ile ilişkili litosferik dilim kopması (slab breakoff) olayına bağlamaktadır (Boztuğ, 1998; Aydın vd., 2001; İlbeyli vd., 2004; Kadığlu vd., 2006; Köksal ve Göncüoğlu, 2008). Erken evreyi temsil eden ve Syn-COLG olarak kabul edilen S-tipi granitlerin incelen ve kısalan kıta kabuğun kısmi ergimesi ile oluştuğu kabul edilse de mantodan türemiş mafik ergiyik içerip içermediği tartışma konusudur (Akıman vd., 1993; Ekici ve Boztuğ, 1997; Aydın vd., 1998). Orta Anadolu'da I-tipi granitler ile birlikte yaygın gelişen ve I-tipi granitlere göre nadir mafik mineral anklav içeren S-tipi granitlerin oluşumu farklı şekillerde yorumlanmıştır. Bazı araştırmacılar, S-tipi granitlerin Orta Anadolu Kristalen Kompleksine ait metasedimanterlerin bölgesel metamorfik koşullar esnasında kısmi ergimesi ve dehidrasyonu ile geliştiğini savunmuşlardır (Boztuğ, 1998; Tatar ve Boztuğ, 2005). Erken evreyi temsil eden löko-granitler ise metasomatize olmuş üst mantodan türeyen ergiyiklerin kıtasal kabuğa enjeksiyonu ile kitasal kabuğun kısmi ergimesi modeliyle açıklanmıştır (İlbeyli vd., 2004; Kadığlu vd., 2006). I-tipi ve kalk-alkalen magmatizması ile karakterisitik olan Post-COLG granitleri, bazı araştırmacılara göre sıcak astonosferin neden olduğu litosferin delaminasyonu ve alt kıta kabuğunun ergimesiyle gelişmiştir (Akıman vd., 1993; Ekici ve Boztuğ, 1997; Boztuğ, 1998; Aydın vd., 2001). İlbeyli vd. (2004) ve Kadığlu (2006) ise I-tipi (monzonitesuit) ve A-tipi (syenite-suite) magmatizmasının gelişmesinde alt kıta kabuğu ergimesiyle birlikte dalan litosferin dilim kopmasının da etkili olduğunu savunmuşlardır. Orta Anadolu'da farklı zamanlarda gelişen magmatizmanın oluşum mekanizmaları farklı araştırmacılar tarafından farklı şekillerde yorumlansa da oluşumu geç gerçekleşen A-tipi granitoyidlerin çarpışma sonrası gerilme rejimi altında litosferik incelme ile geliştiği ve S-tipi / löko-granitlerden I- ve A-tipi plütonik kayaçlara doğru manto katkı oranının yüksek değerlerde olduğu yönünde hem fikirdirler (Ekici ve Boztuğ, 1997; Aydın vd., 1998; Boztuğ, 1998; Aydın vd., 2001; Köksal vd., 2001; Kadıŏlu vd., 2006; Köksal ve Göncüoğlu, 2008).

\section{KATKI BELIRTME}

Bu çalışma Nevşehir Hacı Bektaş Veli Üniversitesi Bilimsel Araştırma Projeleri Birimi tarafından 2012/3 nolu proje kapsamında desteklenmiştir. Yazarlar, arazi çalışmaları esnasında yardımlarından dolayı Dr. Ahmet Orhan'a teşekkür ederler. Ayrıca, makaleye olumlu eleştiri ve katkılarından dolayı Dr. Taner Ekici ve diğer hakeme teşekkür ederler.

\section{EXTENDED SUMMARY}

Petrological and geochronological studies on plutonic rocks in Central Anatolia show that a variety of plutonic rocks developed during three different magmatic phases in Late Cretaceous - Early Tertiary. These plutons reflecting different source characteristics can be attributed to a subduction magmatism based on field, petrographic and geochemical properties The leucogranites representing early phase granite have high-K series, calc-alkaline, peraluminous 
and C-(or S) type melt character. C-type granitoids derived from upper crustal sedimentary rocks are assigned as the products of syn-collisional magmatism. The quartz monzonitic rocks of the late phase are characterized by high-K to shoshonitic series, calc-alkaline, metaluminous and H- (or I-) type melt composition. H-type granitoids, which are the products of post-collisional magmatism, frequently include mafic microgranular enclaves and K.feldspar megacrysts. Their formation may be attributed to the contribution of mafic magma derived from the partial melting of lithospheric mantle and/or slab break-off due to upwelling hot asthenosphere. The compositions of monzonitic and syenitic rocks at the final stage vary between silica-saturated and silica-unsaturated. They are slightly to strongly alkaline and A-type melt character. A-type plutonic rocks are considered to be formed by lithospheric thinning as a result of tensional regime following post-collisional magmatism.

In this study, the field, petrographic and geochemical properties of plutonic and/or subvolcanic rocks in the Cappadocia (Nevşehir) Region are summarized. The main aim of this paper is to discuss the petrogenetic processes in the study area by comparing with the diverse magmatism in Central Anatolia. The study area covers the Bayramhacl, İdişdă̆ı, Göynük, Karadağ, Yeşilöz, Akçataş plutonic and/or subvolcanic as well as Actgöl plutonic rocks cropping out in the northern and southern part of the Nevşehir province (Fig. 2 and 3). In the Cappadocia region, three types of plutonic and/or subvolcanic rocks with different texture, mineralogical and geochemical properties are exposed. These rocks reveal monzogranite (quartz abundance is high), quartz monzonite / monzodiorite (quartz abundance is moderate) and monzonite (quartz abundance is low) / phonolitic tephrite and tephritic phonolite (quartz free) compositions (Table 1; Fig. 5).

The Actgöl pluton, exposed at the south of Nevşehir, exhibits monzogranite composition
(Fig. 5) and includes rarely mafic microgranular enclave (MME) and K.feldspar megacrysts (Fig. 4a). While the major minerals in the Acigöl pluton are quartz, plagioclase, K.feldspar, biotite; the accessory minerals are titanite, apatite and opaque. The leucogranite is subalkaline, high-K series and calc-alkaline and I type melt character. The field, petrographic and geochemical features of the Actgöl pluton typical indicate crustal derived granitoid. The Actgöl pluton plots within post-COLG area and it typically has low $\mathrm{Ba}, \mathrm{Ce}$, Hf and $\mathrm{Zr}$ content. Moreover, the pluton's LREE ratio $\left((L a / Y b)_{n}=4.58-12.11\right)$ is lower than other plutonic / subvolcanic rocks in the Cappadocia Region.

In the northern section of Nevşehir, magmatic rocks have quite different compositions which are in monzogranite - quartz monzonit / monzodiorite - monzonite - phonolitic tephrite / tephritic phonolite composition. Quartz monzonitic / monzodioritic rocks contain dominantly $M M E$ and K.feldspar megacrysts. Furthermore, monzonitic rocks are in contact with the porphyritic subvolcanic rocks including feldspar or leucite megacrysts. Quartz monzonite / monzodiorite are composed of plagioclase, K.feldspar, quartz, amphibole, biotite as the main constituents. Accessory and secondary minerals are comprised by pyroxene, titanite, apatite opaque and epidote, chlorite, sericite, calcite, kaolinite, respectively. These rocks are characterized by subalkaline (Fig. 7), high-K to shoshonitic series (Fig. 8a), calc-alkaline and alkali-calcic (Fig. 8b) as well as showing I-type (Fig. 8c) melt composition. Macro and mineralogical properties of these rocks indicate magma mixing processes which can be summarized as; (a) including MME and K.feldspar megacrysts (Fig. 4b, c), (b) some plagioclase minerals show a sieved texture and lath-shaped small plagioclase within large plagioclase, (c) poikilitic textured orthoclase including amphibole, biotite, plagioclase and apatite crystals (Fig. 6c), (d) some amphibole 
and biotite present appinitic texture with quartz, plagioclase and opaque inclusions (Fig. 6b), (e) acicular apatite inclusions in MME (Fig. 6c). In ocean ridge normalized element diagrams, quartz monzonitic / monzodioritic rocks reveal enriched large ion lithophile elements (LILE: $K, R b, B a$ ) compared to high field strength elements (HFSE: $\mathrm{Ta}, \mathrm{Nb}, \mathrm{Hf}, \mathrm{Zr}, \mathrm{Y}$ ) which are the indicators of magma originated in a subduction zone and/or collisional tectonic setting. All the samples plot within post-COLG area. On the other hand, the LREE ratios for these rocks vary in a wide range $\left((L a / Y b)_{n}=12.06-33.78\right)$. The field, petrographic and geochemical features of the Akçataş, Göynük, Yeşilöz plutons and Karadağ subvolcanite typically point out subcontinent and lithospheric mantle derived granitoids. Some samples of İdişdağl and Bayramhact plutons represent these properties.

Monzonitic and phonolitic tephrite / tephritic phonolite rocks have different mineral paragenesis (Table 1). Monzonitic rocks are composed of feldspar (albite, orthoclase), amphibole, pyroxene as the main constituents (Fig. 6f). Accessory and secondary minerals are comprised by quartz, xenotime, opaque and chlorite, sericite, calcite, kaolinite, respectively. Phonolitic tephrite / tephritic phonolite rocks contain orthoclase, nepheline, pyroxene, nozean and melanite (Fig. $6 g, h, j, k$ ). These rocks have alkalen (Fig. 7and Fig. 8b), shoshonitic series (Fig. 8a) and I-type (Fig. 8c) melt composition. Some İdişăgl and Bayramhacı plutonic rock samples and particularly subvolcanic and aplite dyke samples present alkalen character. Although these samples plot both within post-COLG and at the boundary of WPG, they have low Ba and high $K, R b$, Th values which reflect WPG after post-COLG. Also, these rocks have higher LREE ratio $\left((\mathrm{La} / \mathrm{Yb})_{n}=23.29-82.17\right)$ than other plutonic rocks in the Cappadocia Region. The field, petrographic and whole-rock chemistry data indicate that all magmatic rocks are formed by a subduction magmatism and the contribution of subcontinent and lithospheric mantle increases towards A-type plutons. The petrographic and geochemical properties of magmatic rocks within the Cappadocia Region are quite compatible with the Central Anatolia Plutonic rocks.

\section{ORCID}

Ayşe Orhan (D)

http://orcid.org/0000-0001-8103-5376

Mehmet Demirbilek (D)

http://orcid.org/0000-0003-2749-5560

\section{DEĞINILEN BELGELER}

Akıman, O., Erler, A., Göncüoğlu, M.C., Güleç, N., Geven, A., Türeli, T.K., Kadığlu, Y.K., 1993. Geochemical characteristics of granitoids along the western margin of the Central Anatolian Crystalline Complex and their tectonic implications. Geological Journal, 28, 371-382.

Atabey, E., Tarhan, N., Yusufoğlu, H., Canpolat, M., 1988. Hacıbektaş, Gülşehir, Kalaba (Nevşehir)Himetdede (Kayseri) Arasının Jeolojisi. MTA Derleme Rapor No: 8523 (yayınlanmamış).

Atabey, E., 1989. 1:100 000 ölçekli Açınsama Nitelikli Türkiye Jeoloji Haritaları Serisi Kayseri-H19 paftası. MTA Genel Müdürlüğü (yayınlanmamış).

Aydar, E., Schmitt, A.K., Çubukçu, H.E., Akın, L., Ersoy, O., Sen, E., Duncan, R.A., Atici, G., 2012. Correlation of Ignimbrites in the Central Anatolia Volcanic Province Using Zirkon and Plagioclase Ages and Zircon Composition. Journal of Volcanology and Geothermal Research, 213- 214, 83-97.

Aydın N.S., 1984. Orta Anadolu Masifinin Gümüşkent B. (Nevşehir) Dolayında Jeolojik-Petrografik İncelemeler. Doktora Tezi, 400 s., Ankara Üniversitesi Fen Fakültesi Jeoloji Bölümü (yayınlanmamış).

Aydın, N.S., 1991. Orta Anadolu Masifi Akçataş Granitinin (Nevşehir) Petrografik Özellikleri. MTA Dergisi, 112, 117-133.

Aydın, N.S., Göncüoğlu, M.C., Erler, A., 1998. Latest Cretaceous Magmatism in the Central 
Anatolian Crystalline Complex: Review of Field, Petrographic and Geochemical Features. Turkish Journal of Earth Science, 7, 259-268.

Aydın, N.S., Malpas, J., Göncüoğlu, M.C., Erler, A., 2001. A Review of the Nature of Magmatism in Central Anatolia during the Mesozoic PostCollisional Period. International Geology Review, 43, 695-710.

Barbarin, B. 1990. Granitoids: main petrogenetic classifications in relation to origin and tectonic setting. Geological Journal, 25, 227-238.

Barbarin, B., 1999. A reviev of the relationships between granitoid types, their origins and their geodynamic environments, Lithos, 46, 605-626.

Becker, H., 1956. Gülşehir ile Hacıbektaş Arasındaki Bölgenin Kayseri'nin Batısı Jeolojisi. MTA Derleme Rapor No: 2578 (yayınlanmamış).

Bonin, B., 1990. From orogenic to anoregenic settings: evolution of granitoid suites after a major orogenis. Geological Journal, 25, 261-270.

Boztuğ, D., 1998. Post-Collisional Central Anatolian Alkaline Plutonism, Turkey. Turkish Journal of Earth Sciences, 7, 145-165.

Chappell, B.W., White, A.J.R., 1974. Two contrasting granite types. Pacific Geology, 8, 173-174.

Chappell, B.W., White, A.J.R., 2001. Two contrasting granite types: 25 years later. Australian Journal of Earth Sciences, 48, 489-499.

Condie, K.C., 1989. Plate tectonics and crustal evolution, third ed.: New York, NY, Pergman Press.

Dönmez, M., Akçay, A.E., Türkecan, A., 2005. 1:100 000 ölçekli Türkiye Jeoloji Haritaları Kayseri-K34 paftası. MTA Genel Müdürlüğü (yayınlanmamış).

Ekici, T., 1997. Yozgat Batoliti Yozgat Güneyi Kesiminin Petrolojisi. Yüksek Lisans Tezi, 75 s., C.Ü. Fen Bilimleri Enstitüsü (yayınlanmamış).

Ekici, T., Boztuğ, D., 1997. Anatolid-Pontid Çarpışma Sisteminin Pasif Kenarında Yeralan Yozgat Batolitinde Syn-COLG ve Post-COLG Granitoyid Birlikteliği. Yerbilimleri, 30, 519-538.

Erler, A., Kuşcu, İ., Dirik, K., Ulu, Y. ve Yavuz, N., 1996. Orta Anadolu Kristalen Karmaşı̆̆ı'nın Metalojenisi. ODTÜ Araştırma Fonu Proje No: 94-03-09-02, Ankara.
Göncüoğlu, M.C., Erler, A., Toprak, G.M.V., Olgun, E., Kuşçu, İ., 1991. Orta Anadolu Masifinin Batı Bölümünün Jeolojisi, Bölüm 1: Güney kesim. TPAO Rapor No: 2909 (yayımlanmamış).

Hibbard, MJ., 1991. Textural anatomy of twelve magma-mixing granitoid systems. In: Didider, J., Barbarin B. (Eds.) Enclaves and Granite Petrology. Elsevier, Amsterdam, pp. 431-444.

Irvine, T.N., Baragar, W.R.A., 1971. A guide to the chemical classification of the common volcanic rocks. Canadian Journal of Earth Sciences, 8: 523548.

İlbeyli, N., Pearce, J.A., Thirlwall, M.F., Mitchell, J.G., 2004. Petrogenesis of collision-related plutonic in Central Anatolia, Turkey. Lithos, 72, 163-182.

Kadığlu, Y.K., Dilek, Y., Foland, K.A. 2006. Slab break-off and syncollisional origin of the Late Cretaceous magmatism in the Central Anatolian crystalline complex, Turkey. Geological Society of America Special Paper, 409, 38 1-415.

Köksal, S., 1996. İdiş Dağ1 - Avanos Yöresi'nin Jeolojik ve Petrolojik Özellikleri (Nevşehir Orta Anadolu). Yüksek Lisans Tezi, 141 s., Orta Doğu Teknik Üniversitesi Fen Bilimleri Enstitüsü (yayınlanmamış).

Köksal, S., Göncüoğlu, M.C., 2008. Sr and Nd Isotopic Characteristics of some S-, I and A-type granitoids from Central Anatolia. Turkish Journal of Earth Sciences, 17, 11-127.

Köksal, S., Göncüoğlu, M.C., Floyd, P.A., 2001. Extrusive members of postcollisional A-Type magmatism in Central Anatolia: Karahıdır volcanics, İdişdağı-Avanos area, Turkey. International Geology Review, 43, 683-694.

Maniar, P.D., Piccoli, P.M., 1989. Tectonic discrimination of granitoids. Geological Society of America Bulletin 101, 635-643.

MTA, 2001. 1:25.000 ölçekli Jeoloji Haritaları.

MTA, 2005. 1:100.000 ölçekli Türkiye Jeoloji Haritalar1, Kayseri-K34 paftas1.

Nakamura, N., 1974. Determination of REE, Ba, Mg, $\mathrm{Na}$ and $\mathrm{K}$ in carbonaceous and ordinary chondrites. Geochimica et Cosmochimica Acta 38, 757-775.

Orhan, A., Demirbilek, M., 2014. Kapadokya Bölgesi (Nevşehir) Plütonik Kayaçların Mineralojik, 
Petrografik ve Jeokimyasal Özelliklerinin İncelenmesi. Nevşehir Hacı Bektaş Veli Üniversitesi Bilimsel Araştırma Projesi, Proje No: 2012/3, 71 s. (yayınlanmamış).

Pearce, J.A., Harris, N.B.W., Tindle, A.G. 1984. Trace element discrimination diagrams for the tectonic interpretation of granitic rocks. J. Petrol., 25: 956983.

Pertermann, M., Hirschmann, M.M., Hametner, K., Günther, D., Schmidt, M.W., 2004. Experimental determination of trace element partitioning between garnet and silica-rich liquid during anhydrous partial melting of MORB-like eclogite. Geochemistry Geophysics Geosystem An Electronic Journal of Earth Sciences, 5, 1-23.

Reichardt, H., Weinberg, R.F., 2012. Hornblende Chemistry in Meta- and Diatexites and its Retention in the Source of Leucogranites: an Example from the Karakoram Shear Zone, NW India. Journal of Petrology, 0, 1-32.

Rickwood, P.C., 1989, Boundary lines within petrologic diagrams which use oxides of major and minor elements: Lithos, v. 22, p. 247-263.
Seymen, İ., 1981. Kaman (Kırşehir) Dolayında Kırşehir Masifinin Stratigrafisi ve Metamorfizmas1. Türkiye Jeoloji Kurultayı Bülteni, 24/2, 101-108.

Streckeisen, A., 1976. To each plutonic rock its proper name. Earth Science Reviews 12 (1), 1-33.

Sun, S.S., McDonough, W.F., 1989. Chemical and isotopic systematics of oceanic basalts: implications for mantle composition and processes. In: Saunders, A.D., Norry, M.J. (Eds.)., Magmatism in ocean basins. Geol. Soc. Lond. Spec. Publ., 42: 313-345.

Tatar, S., Boztuğ, S., 2005. The syn-collisional Danaciobas biotite leucogranite derived from the crustal thickening in central Anatolia (Kırıkkale), Turkey. Geological Journal 40, 571-591.

Yılmaz, S., Boztuğ, D., 1994. Granitoyid Petrojenezinde Magma Mingling/Mixing Kavramı. Jeoloji Mühendisliği Dergisi, 44-45, 1-20. 